\title{
LA CERÁMICA COMÚN DE MESA, COCINA Y DESPENSA EN EL ALTO DUERO DURANTE EL PERIODO BAJOIMPERIAL: UN ENSAYO DE CLASIFICACIÓN
}

\author{
Late Roman Coarse Ware in Upper Duero valley at Late Roman \\ Empire: a classification assay
}

\author{
Jesús Bermejo Tirado ${ }^{1}$
}

Recibido el 3 de abril de 2012. Aceptado el 2 de agosto de 2012

\begin{abstract}
Resumen. En este artículo hemos tratado de realizar un primera sistematización del estudio de la cerámica común y de despensa en la región del Alto Duero durante el Bajo Imperio (grosso modo mediados del siglo III d. C.- primeras décadas del V d. C.). Para ello establecemos una propuesta tipológica a partir de una serie de contextos cerámicos conocidos. Las categorías de clasificación obtenidas se basan en una metodología que incluye tres niveles interconectados de análisis: tecnología, funcionalidad y morfología.

Palabras clave: Cerámica común romana, Alto Duero, Bajo Imperio, propuesta metodológica, clasificación tipológica.
\end{abstract}

Abstract. In this paper we have faced the systematization of the Late Roman Coarse Ware productions recorded in the Upper Duero Valley Region between the III and the V centuries A. D. We develop a typological proposal for this kind of finds in base of the analysis of four well recorded case-studies. The categories here exposed are obtained by a methodological approach which includes three linked analysis levels: technology, functionality and morphology.

Key words: Late Roman Coarse Ware, Upper Duero Valley, Late Roman Empire, Methodology, Typological proposal.

\section{INTRODUCCIÓN ${ }^{2}$}

En las dos últimas décadas se han publicado varios estudios dedicados al análisis de determinados tipos de cerámica común romana (para el ámbito hispano vid. Sánchez Sánchez 1992; Aquilué Abadías y Roca Roumens 1995; Fernández García 1999; Alcorta Irastorza 2001; Doval Galán 1997-98; Vázquez Gómez y Doval Galán 1996; Fernández Ochoa y Zarzalejos Prieto 2001; Aguarod Otal 2003;
Aguarod Otal, Feliú Ortega y Martín 1995; Luezas Pascual 1999, 2001b; Puente 2002; Puente e Illarregui Gómez 2000; Serrano Ramos 2000; Macías Solé 1999; Martínez Salcedo 2004; Buxeda i Garrigós et al. 2005; Tsantini 2004; Cau Ontiveros 2008; Hevia González 2009, 2009b, Járrega 2009; Peinado Espinosa 2010). La gran mayoría de estos trabajos han llamado la atención sobre la propia ausencia de una definición precisa (o por lo menos de consenso) que sirva para definir claramente este tipo de producciones cerámicas

(1) jesusbermejotirado@gmail.com

(2) Quisiera agradecer al director del Museo Numantino de Soria D. Elias Terés y a su conservadora Marian Arlegui por las facilidades prestadas y por su amabilidad durante el periodo de revisión algunos de los materiales objeto de estudio en este trabajo. Agradecimiento que hago extensivo a María Mariné Directora del Museo de Avila por permitirnos el acceso a la documentación original de las intervenciones arqueológicas desarrolladas en la villa romana de Las Cuevas de Soria. Agradezco a Alejandro Quevedo (Universidad de Murcia) algunas de las precisiones terminológicas utilizadas en este trabajo. Por último quisiera también agradecer las sugerencias planteadas por los evaluadores anónimos que han servido para corregir y mejorar algunos aspectos de este trabajo. 
del periodo romano. De hecho, como ya apuntara C. Panella (1996: 9-10), se puede afirmar que aquello que se suele designar en la bibliografía arqueológica con el nombre de "cerámica común" se refiere más bien una denominación establecida por exclusión. En ocasiones, el único criterio de adscripción de una pieza a esta categoría es su no pertenencia a otras categorías cerámicas romanas con un origen productivo y un rango de morfologías claramente definidas por la tradición historiográfica precedente (terra sigillata, paredes finas, etc.) (Bats 1996: 481-484). Las características tecnológicas de estas últimas manufacturas así como la evolución morfológica genérica de sus variantes permitían una fuerte homogeneidad para cada uno de los tipos sistematizados por los sucesivos estudiosos. Algo que, en principio, no era posible conseguir con todas las producciones denominadas con la categoría de cerámica común.

Dado que el objetivo fundamental para el estudio de los conjuntos cerámicos en la arqueología romana de gran parte de los siglos XIX y XX era el de establecer referencias cronológicas (Adams y Adams 1991: 157-169; Reynolds 2008) no debe extrañarnos que sea precisamente en estos grupos definidos con precisión (sigillata, lucernas, ánforas, etc.) en los que normalmente se concentra el estudio de los productos registrados en contextos romanos.

La estandarización, que podriamos denominar proto-industrial, de manufacturas cerámicas como la TSI, TSSG, TSA, las producciones de paredes finas o las ánforas, es una de las razones fundamentales que permiten explicar la orientación cronotipológica que tradicionalmente ha primado en el estudio de la cerámica romana. La prueba más concluyente de esta afirmación la encontramos en la tendencia a individualizar el estudio de una determinada producción dentro de los conjuntos materiales documentados en el registro arqueológico de un yacimiento, y que en muchas ocasiones se desarrolla sin atender a su contexto estratigráfico (Allison 1997).

Pero en el caso de las Ilamadas cerámicas comunes romanas, este paradigma no puede ser aplicado del mismo modo que en el caso de otras producciones. Las múltiples variantes tecnológicas, productivas, funcionales y morfológicas de las manufacturas habitualmente agrupadas bajo esta categoria (que incluyen cerámicas modeladas y torneadas, producciones domésticas, locales, regionales e importaciones de centros productivos proto-industriales así como diferentes tipos de materias primas y cadenas operativas de producción) nos sugieren que en lugar del estudio de la cerámica común debemos hablar más bien del estudio de las "cerámicas comunes" en plural (Bats 1996: 481). La existencia un amplio espectro de diversas facies con ámbitos de implantación y evoluciones formales diferentes, bien por la inmanencia de determinadas formas, bien por la existencia de innumerables variantes locales, imposibilita el establecimiento de cronotipologías con un ámbito de aplicación tan extenso como los que hemos obtenido por medio del estudio de la terra sigillata.

Sin embargo, este hecho no significa que el estudio de la cerámica común no sea una cuestión fundamental para la historia de la sociedad y la economía romana. Cabe recordar, como ya señaló en su día Peacock (1982: 75, 90-91), que la producción local y regional de cerámica común supuso un porcentaje importante de la producción alfarera total de época romana. Por este motivo el estudio sistemático de este tipo de cerámicas, de sus modos de manufactura y de su distribución como objeto de consumo, nos permite documentar la evolución histórica de muchos aspectos de la vida y las actividades cotidianas de los antiguos habitantes del mundo romano.

Este trabajo pretende exponer una propuesta para el análisis de este tipo de cerámicas a partir de su aplicación a un caso de estudio concreto: la región del Alto Duero, más concretamente el curso alto del valle del Duero a su paso por el territorio de las provincias de Soria y Burgos, durante el periodo bajoimperial. Pretendemos establecer la primera aproximación sistemática a la cuestión en el contexto altoduriense al tiempo que desarrollar una propuesta metodológica que pueda ser útil para ulteriores estudios.

\section{MARCO CRONOLÓGICO DE APLICACIÓN}

En el transcurso de nuestro proyecto doctoral sobre la arqueología de los espacios domésticos de dicho periodo tuvimos la oportunidad de revisar una parte de los contextos materiales procedentes de yacimientos romanos con secuencias de ocupación que abarcaban diversos momentos del Bajo Imperio romano (mediados del siglo III d. C.-primera mitad del siglo $\mathrm{V} d$. C.). Todos los contextos materiales analizados (Figura 1) provenían de niveles arqueológicos generados por la ocupación residencial permanente de dichos espacios por parte de sucesivas unidades domésticas.

En la mayoría de los casos dichos depósitos fueron generados en el transcurso de procesos normales de ocupación y abandono doméstico, es decir, son el resultado de procesos de formación dilatados en el tiempo. En otros casos, de forma excepcional, la acción súbita de una destrucción súbita ha servido para generar aquello que podemos denominar como "abandonos de facto" (Schiffer 1987: 89; Lamotta y Schiffer 1999).

Con relación al tipo de estudio que aquí planteamos la principal diferencia entre ambos tipos de depósito se refiere al marco cronológico de los contextos materiales en ellos documentados. Los estratos formados a partir de procesos formativos normales tienen depósitos que en determinados casos pueden asociarse a la acción de varias generaciones sucesivas (Schiffer 1983). Por lo tanto los indicadores cronológicos situados en dichos contextos raramente permiten establecer una adscripción cronológica concreta. 


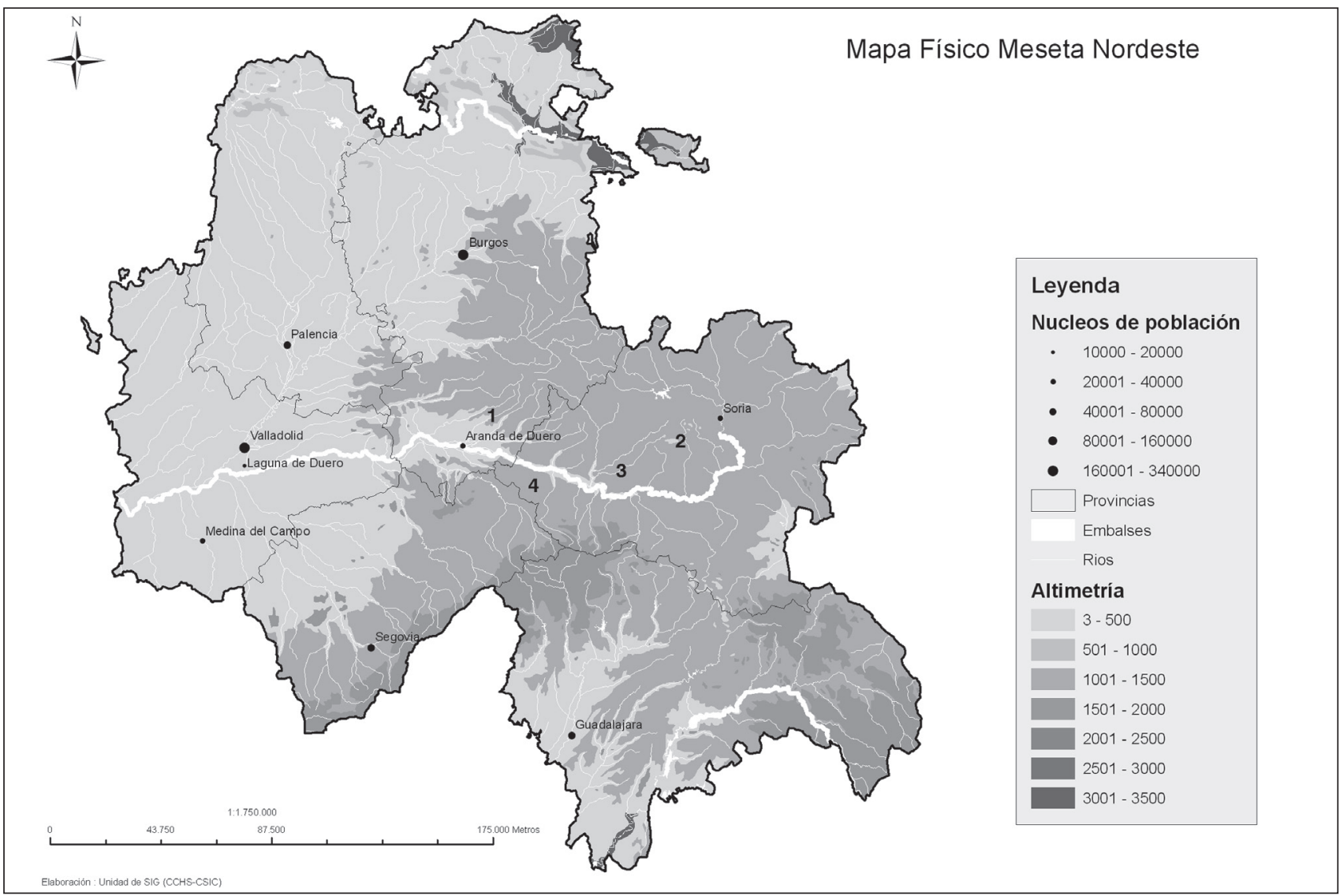

A Figura 1. Mapa físico de las provincias de Guadalajara, Soria, Burgos, Segovia, Palencia y Valladolid con la situación de los principales conjuntos cerámicos analizados en nuestro trabajo. 1- Baños de Valdearados (Burgos). 2- Cuevas de Soria (Soria). 3- Casa de los Plintos (Uxama Argaela, Soria). 4- San Pedro de Valdanzo (Soria). Elaboración: Unidad de SIG del CCHS-CSIC.

\section{PRINCIPALES CONJUNTOS MATERIALES ANALIZADOS}

Considerando el objeto del presente estudio la fuente fundamental de información ha de proceder necesariamente de yacimientos con un registro arqueológico bien documentado por medio diversos de trabajos de excavación. Este requisito nos ha llevado a descartar algunos conjuntos y tipos cerámicos que, a pesar de tener un indudable interés para nuestro análisis, no poseen un contexto arqueológico preciso o han sido documentados por medio de diversos trabajos de prospección o de hallazgos fortuitos.

Presentamos ahora una breve descripción de los principales yacimientos de los que hemos extraído los conjuntos materiales que nos han permitido establecer nuestro ensayo de clasificación.

\subsection{La villa romana de Cuevas de Soria}

(Fig. 1: n. ${ }^{\circ}$ 2)

Esta villa, una de las más famosas del valle del Duero (para una sintesis historiográfica más detallada vid. Mariné Isidro 2007) es también una de las que menor número de publicaciones ha suscitado.
El conocimiento del trazado de la mayor parte de la pars urbana de la villa, se debe a las intervenciones que en ella efectuó D. Blas Taracena Aguirre en los años veinte y de la que apenas se conserva documentación original (Taracena Aguirre 1930). Unas décadas más tarde, en las campañas dirigidas por la Dra. Mariné Isidro en la década de los ochenta (Expedientes Mariné Isidro 1980, 81, 82, 84, 85, 86 informes técnicos depositados en el Museo Numantino de Soria ref. en Bermejo Tirado 2011: 783-920), se recuperaron la mayor parte de los datos y materiales que forman la base fundamental del presente trabajo. Estos trabajos de excavación permitieron completar nuestro conocimiento sobre las estructuras que formaron parte de la villa y de su secuencia de ocupación.

La identificación de una primera fase de ocupación de este asentamiento rural pudo situarse en torno al siglo II d. C. (Bermejo Tirado 2011: 906-907). A esta fase inicial, escasamente documentada en este núcleo de ocupación, le sucede una fase posterior que abarca una horquilla cronológica comprendida entre el siglo III d. C. y algún momento de los siglos $\mathrm{V}-\mathrm{VI}$ d. C. Los conjuntos cerámicos analizados pertenecen a las fases de ocupación y abandono de las estructuras termales (Mariné Isidro 1984, para una explicación precisa de los contextos vid. Bermejo Tirado 2011: 907) así 
como los pozos y "encaños de piedra tirada" (Mariné Isidro 1985) pertenecientes a los momentos iniciales de la segunda fase de ocupación correspondiente a la villa bajoimperial.

\subsection{La villa de San Pedro de Valdanzo}

(Fig. 1: n. ${ }^{\circ}$ )

La excavación de urgencia de esta villa se realizó motivada por la necesidad de proteger sus mosaicos (Jimeno Martínez, Argente Oliver y Gómez-Santacruz 1988-89: 419) de la destrucción a la que estaban siendo sometidos por las tareas agrícolas emprendidas en el yacimiento. Dichos trabajos de excavación permitieron identificar una serie de niveles arqueológicos correspondientes a un asentamiento rural romano con una ocupación comprendida entre los siglos II y III d. C. y que se apoyaba directamente sobre la roca natural (Jimeno Martínez, Argente Oliver y Gómez-Santacruz 1988-89: Figura 2). Este nivel de ocupación estaba sellado por el rudus del llamado de algunos de los citados pavimentos musivos.

Sobre esta primera fase de ocupación se documentaron los restos de una villa romana de peristilum con depósitos de ocupación y abandono fechados por medio de diversos hallazgos cerámicos entre los siglo IV y V d. C (Jimeno Martínez, Argente Oliver y Gómez-Santacruz 1988-89: 422-423). De esta fase proceden los conjuntos materiales analizados en este trabajo. Toda esta segunda fase de ocupación se encontraba mezclada con los restos de material constructivo procedentes del derrumbe de la villa. La ausencia de indicios claros de destrucción súbita nos sugiere que su abandono definitivo se produjo de forma progresiva a lo largo de la siguiente centuria.

\subsection{La villa de Baños de Valdearados}

(Fig. 1: n. ${ }^{\circ}$ 1)

El descubrimiento, que podemos calificar de fortuito, de esta villa se produjo en el año 1972, cuando una máquina excavadora se estaba encargando de nivelar el terreno de la finca en la que se encontraba este asentamiento (Argente Oliver 1979: 8). Unos dias más tarde, previo informe de la Comisaria General de Excavaciones Arqueológicas, se inicia la excavación de urgencia del yacimiento con el objetivo de proteger y comprobar el estado de conservación de las estructuras afectadas por la acción de la excavadora (Argente Oliver 1979: 9).

A lo largo de tres sucesivas campañas de excavación se practicaron una serie de catas y sondeos sobre las estructuras detectadas. Estas intervenciones permitieron reconocer los restos constructivos de algunos sectores de una villa señorial ornamentada con decoración arquitectónica y pavimentos de mosaico. La mayor parte de la superficie excavada presentaba una estratigrafía homogénea (Argente Oliver 1979: 40-43): un primer nivel superficial formado por el manto vegetal, un segundo nivel intermedio con algunos restos constructivos y escasos materiales cerámicos de diversa época. Un tercer nivel, con unidades estratigráficas identificables con una fase de abandono y destrucción, estaría compuesto por una mezcla de material constructivo (tegula e imbrex), restos de decoración arquitectónica, así como la mayor parte de los contextos cerámicos -fechados por J. L. Argente (1979: 125-126) entre finales del siglo IV y el siglo $\mathrm{V} \mathrm{d}$. C.- de los que proceden los materiales objeto del presente estudio.

Por debajo de las salas pavimentadas con mosaicos se documentaron restos estructurales (Argente Oliver 1979: Figura 11) a los que se asociaban depósitos de ocupación sellados con niveles de cenizas. Estos hallazgos sirven para documentar (aunque de forma imprecisa) la existencia de un asentamiento rural anterior a la construcción de la villa romana.

\subsection{La Habitación 7 de la Casa de los Plintos (Uxama Argaela) (Fig. 1: n. ${ }^{\circ}$ 3)}

Situada en el sector central de la retícula urbana de la ciudad de Uxama Argaela, la Casa de los Plintos es una de las pocas domus urbanas que conocemos en toda su extensión en la región del Alto Duero. A la espera de la sistematización definitiva de todos sus contextos materiales (un avance se ha publicado en diversos trabajos vid. García Merino 1990, 1991, 1994; García Merino, Sánchez Simón y Burón Álvarez 2007) todavía en proceso de estudio, la publicación de un contexto situado en la Habitación n ${ }^{\circ} 7$ del conjunto (García Merino, Sánchez Simón y Burón Álvarez 2009) nos ha permitido obtener una fuente de información muy precisa sobre la cultura material del siglo III d. C. en la región.

Esta habitación, situada en la línea de la fachada de la casa, ha conservado el depósito de destrucción más potente del asentamiento, y el menos afectado por los procesos postdeposicionales que afectaron este sector de la ciudad (García Merino, Sánchez Simón y Burón Álvarez 2009: 225-226).

\section{CRITERIOS METODOLÓGICOS}

De forma esquemática hemos de subrayar que nuestra propuesta clasificatoria se ha estructurado en tres diferentes niveles. El primero de ellos, el tecnológico, se ha orientado fundamentalmente a la sistematización de los indicios de procesos productivos o cadenas operativas (Lemonnier 1976, 1986, 1992) documentadas en el análisis de las propias piezas. El segundo nivel, de corte funcional, se refiere fundamentalmente a los contextos de uso y de consumo en los que podemos inscribir estos recipientes cerámicos. Un último nivel de clasificación se refiere a las variantes morfológicas de cada tipo.

Contrariamente a lo que pueda pensarse, esta diferenciación entre niveles de clasificación no pretende estable- 
cer distinciones estancas o jerárquicas. En la práctica del análisis de contextos cerámicos, la interrelación de esos niveles de clasificación se hace evidente. Del mismo modo, nuestra intención era la de integrar las distintas fases de la biografía social (Appadurai 1986) de estas piezas en sus respectivos contextos sistémicos (Schiffer 1972, Peña 2007: 6-17, 319-352) con el objetivo de obtener un ensayo de clasificación unitario aplicable a otros contextos similares.

\subsection{Tecnología}

La ausencia de un programa sistemático de analíticas de pastas nos impide conocer la caracterización química detallada de las distintas arcillas empleadas en la manufactura de estos conjuntos. Este tipo de datos nos permitirían, mediante la práctica de estudios comparativos, plantear posibles circuitos de extracción y distribución de materias primas.

No obstante, un análisis macroscópico detallado nos permite establecer una serie de variantes tecnológicas. Quizá la más básica sea la más básica sea la distinción entre cerámicas modeladas y torneadas. Aunque la producción de cerámicas a mano raramente suele ser objeto de estudio en contextos del periodo imperial romano (algunas excepciones Bonifay 2004: 67; Capelli 1998; Peacock 1982: 80-89, 1984: 6-20; Fulford y Peacock 1984: 157-167; Van der Werff 1984) la documentación de ciertos rasgos y gestos técnicos nos ha permitido identificar algunos productos modelados entre los conjuntos estudiados. La comparación del volumen de las paredes con la composición estructural de la pieza o la presencia de determinadas tipos de digitaciones, la tendencia a las carenas o los perfiles de labio triangulares o ligeramente apuntados son rasgos que se corresponden a gestos técnicos propios del modelado de cerámicas (Kirchner 2007).

También en el caso de las cerámicas torneadas, la documentación de determinados acabados en la superficie interna o externa de las pastas nos puede sugerir la utilización de diversos tipos de tornos (rápidos o de pie vid. Peña y McCallum 2009). La presencia de determinadas configuraciones estructurales -por ejemplo las paredes finas con acabados lisos, o determinados tipos de labios engrosados- tan solo pueden ser producto del trabajo de alfareros expertos que trabajen con tornos rápidos de pie. Además la utilización de este tipo de tornos rápidos o de pie permite la manufactura de una variedad más grande de formas incluso dentro de cada contexto funcional específico.

Otro tipo de proceso tecnológico relacionados con la manufactura de la pieza es la cocción. El análisis macroscópico de las piezas nos ha permitido individualizar diferentes tipos o grupos de pastas, producto tanto de cocciones reductoras como oxidantes, en función de diversas características como la coloración, la textura, el tamaño de los desgrasantes, o el tacto de los fragmentos.
El examen de estos conjuntos no sirve para proponer una primera aproximación a la clasificación de los principales tipos de pastas documentados en la cerámica común de cocina, mesa y despensa en la región durante el periodo bajoimperial:

- Pasta tipo 1: es un tipo producido por medio de cocción reductora muy irregular y escasa regularización térmica. En muchas ocasiones las piezas presentan secciones muy irregulares con bicromías y tipo "sándwich". Los desgrasantes suelen tener un tamaño superior a $1 \mathrm{~mm}$ y habitualmente contiene componentes refractarios. El tacto de estas pastas suele ser muy rugoso y su coloración es similar al tono Munsell N2 2/1. La mayor parte de las pastas de este tipo se han documentado en ollas y cazuelas a mano destinadas a cocina. Podría corresponder con el tipo de pasta denominado como "Cerámica común de pasta sedimentaria no depurada" registrado en un reciente estudio sobre los contextos cerámicos documentados en las Lagunillas (Centeno, Palomino y Villadangos 2010: 128-130).

- Pasta tipo 2: es un tipo de pasta propia de cocciones reductoras, pero más regulares que las anteriores, con desgrasantes normalmente inferiores a $1 \mathrm{~mm}$. El tacto de estas pastas es rugoso y relativamente harinoso, y su coloración oscila entre las gama Munsell 10 YR 3/6;3/7, 3/8. La gran mayoría de pastas asimilables a este tipo pertenecen a recipientes tipo dolium/tinaja destinados al almacenamiento de gran tamaño. Algunos de los rasgos arriba descritos podrían relacionarse con los correspondientes al tipo de pasta denominada como "Cerámica común de pasta sedimanetarioa no depurada" documentado en las Lagunillas (Centeno, Palomino y Villadangos 2010: 128-129).

- Pasta tipo 3: este tipo de pasta es producida por cocciones reductoras más regulares, con desgrasantes de pequeño tamaño. El tacto de estas piezas es alisado, en algunos casos presentan un bruñido muy fino. Su coloración suele ser negro brillante con tonos asimilables al tono Munsell N2 2/2.

- Pasta tipo 4: se trata de piezas con una cocción oxidante bastante irregular (se ha documentado una gran variedad de secciones monocromas, bicromas y tipo "sándwich"). Los desgrasantes son de muy pequeño tamaño y el tacto de las piezas es alisado. Su coloración es tendente a los ocres anaranjados del tipo Munsell 7,5 YR 6/8. Este tipo de pasta tiene rasgos similares a los registrados en los contextos de Las Lagunillas (Centeno, Palomino y Villadangos 2010: 125) para el que se han propuesto paralelos documentados en Quintanilla de 
la Cueza (Illarregui y Puente 2000: 142) o en Almenara de Adaja (Garcia Merino y Sánchez Simón 2001: 121 Figura 10.10).

- Pasta tipo 5: se trata de piezas con una cocción oxidante bastante regular y desgrasantes de pequeño tamaño que a menudo generan exudaciones de tipo calcáreo o salino. El tacto de las piezas suele ser muy liso y las coloraciones presentan variedades entre los beige tipo Munsell 5 YR 6/8-6/9 y otras piezas más parduzcas y grisáceas que podrían asimilarse al tipo de Pasta F de la Cerámica común de Quintanilla de la Cueza (Illarregui y Puente 2000: 123).

- Pasta tipo 6: este tipo de pastas alisadas de cocción oxidante muy regular suele incluir desgrasantes de tamaño casi imperceptible. La coloración de este tipo tiende a aproximarse a tonos rosáceos muy similares al tono Munsell 10 R 8/5. Po.

Para completar este apartado hemos de apuntar que las variaciones en la coloración, dentro de cada uno de los tipos de pasta, no se deben a diferencias térmicas durante el proceso de cocción en el horno o a la utilización de diversos tipos de arcillas. Un reciente estudio realizado por la Dra. Peinado Espinosa (2010: 384) ha demostrado que las variantes cromáticas en este tipo de cerámicas se producen debido a los diversos ritmos en los procesos de enfriamientos de las piezas ${ }^{3}$. La experimentación con hornos alfareros similares ha servido a su vez para refutar la relación directa entre la coloración y acabado final de las cerámicas y las variaciones térmicas registradas durante la cocción de las piezas (Raposo et al. e. p.).

\subsection{Funcionalidad}

Una de las primeras conclusiones a las que podemos a partir de nuestra propuesta de clasificación del marco tecnológico es la existencia de relaciones de correspondencia entre las formas de producción y la orientación funcional de la pieza. La elección de determinados tipos de materia prima, métodos de manufactura o gestos técnicos parece, en muchos casos, estar condicionada por la concepción de la pieza como objeto útil. Esta adecuación ergonómica no siempre se registra, por lo menos de forma tan general, en muchas otras producciones de época romana. En muchos otros tipos de recipientes del periodo es fácil apreciar la inclusión de elementos tecnológicos de producción que responden en un mayor grado a condicionantes de tipo social y cultural ${ }^{4}$ que de tipo utilitario. Tal vez esa sea precisamente una de las características que sirvan para definir con mayor precisión el tipo de productos cerámicos a los que nos referimos en este estudio.

No obstante, la ambigüedad derivada del concepto de "funcionalidad" nos obliga a establecer unas distinciones previas en el marco de nuestro análisis. Dado que la mayor parte de las piezas estudiadas en Arqueología proceden de un contexto arqueológico concreto (Schiffer 1972: 152, Peña 2007: 7-10) la clasificación utilitaria de los objetos contenidos de cada yacimiento excavado está sujeta a las huellas del uso específico que dicho artefacto posea en función de su vida útil (Schiffer 1972: 158 Figura 1). Esa vida útil del objeto, cuyas trazas quedan inscritas en diversos indicadores materiales, que los arqueólogos podemos interpretar para reconstruir la biografía social de cada pieza, está sujeta a lo que en su momento definimos como "contexto funcional" (Bermejo Tirado 2007-2008), es decir, la función de un objeto en relación a su proveniencia en un contexto arqueológico concreto. Un fragmento de dolium (es decir, un recipiente diseñado para el almacenamiento) pudo haber sido reutilizado como teja para la construcción de un espacio doméstico. A pesar de que en otros contextos sistémicos (Schiffer 1972) anteriores el dolium tuviera un uso original distinto en tanto que sujeto a un contexto arqueológico concreto -por ejemplo la unidad estratigráfica formada por el derrumbe del techo de la casa- el contexto funcional de ese fragmento de ánfora sería el de material de construcción.

De regreso a nuestra propuesta de sistematización, ya que lo que pretendemos en este estudio es establecer una propuesta de clasificación genérica, en lugar de establecer diversos tipos de contextos funcionales para cada una de las piezas, tenemos que proponer una categoría genérica en función del diseño específico de cada tipología. Por este motivo hemos de recurrir al concepto de "Intended Vessel Technofuction" (Skibo 1992: 35-38) para establecer diferentes categorías genéricas de clasificación funcional de los recipientes en relación a sus propiedades físicas y morfológicas.

En el marco de nuestra propuesta de clasificación serán tres las categorias funcionales específicas que aplicaremos: cerámicas de cocina, vajilla de mesa y recipientes para el almacenamiento.

\subsection{Morfología}

La existencia de una serie de características morfológicas específicas sirve, en último término, para definir de

(3) Los procesos de enfriamiento al aire serían los responsables de tonos de tipo anaranjado-ocre, debido la inclusión de un mayor número de partículas de oxígeno en la composición de las pastas. Por el contrario, otros procesos de enfriamiento más dramáticos (seguramente mediante la utilización de agua) se relacionarian con gamas cromáticas más beige y grisáceas (vid. Peinado Espinosa 2010: 384).

${ }^{(4)}$ Que en muchos casos van más allá de los condicionantes a los que se hacía referencia en la clásica definición aportada por Mannoni (1972) y reafirmada por los autores de la monografía sobre la cultura material de la villa de Settefinestre (Carandini y Ricci 1985). 
un modo preciso y reconocible la tipología de un recipiente. Dichos rasgos formales pueden estar relacionados con la configuración estructural integral de la pieza (la arquitectura del vaso) o con las variantes formales específicas de sus componentes.

La citada orientación cronológica de los estudios cerámicos del periodo romano, como vía para la datación de los contextos, ha priorizado la delimitación de variantes morfológicas muy concretas como objeto de estudio (Adams y Adams 1991: 157-169). De este modo, cuantas más variantes formales se podian registrar, más perfecta se consideraba la tipología obtenida. De la misma forma, cuantas más variantes formales se ofrecian en una síntesis tipológica, mayores probabilidades hay de poder identificar hallazgos concretos con otros marcadores cronológicos situados en los mismos contextos lo que, en progresión aritmética, nos ofrecería la posibilidad de establecer dataciones más precisas. Además de esto, la oportunidad de identificar la secuencia cronológica en la sucesión de las variantes formales, era identificada en muchos casos como el registro de la evolución lineal de una determinada manufactura a lo largo de la Historia.
Sin entrar en críticas teóricas hacía el "evolucionismo genealógico" implícito en este tipo de enfoques lo que si queremos apuntar es que, en determinadas ocasiones, la presencia de diversas variantes formales no responde tanto al desarrollo cronológico del trabajo de sucesivas generaciones de maestros y aprendices como a la variedad de gestos técnicos que, en un momento dado, uno o varios artesanos contemporáneos puedan aplicar en la producción del mismo tipo de recipientes (Schiffer y Skibo 1997). El desarrollo de múltiples trabajos de corte etnoarqueológico ha servido para documentar situaciones similares en diversos ámbitos culturales (Arnold 1984, 1985; Arnold III 2000; Blinman 1993; Deetz 1965; Dobres y Hoffman 1994; Longacre 1991).

La documentación de un tipo de recipiente conocido con una variante formal desconocida (por ejemplo un labio o una base con una forma peculiar, o la aplicación de una decoración diferente) no es suficiente criterio para el establecimiento de una nueva categoría tipológica. Es necesaria su documentación generalizada en un número significativo de contextos la que nos tiene que llevar a proponer el establecimiento de una nueva tipología formal.

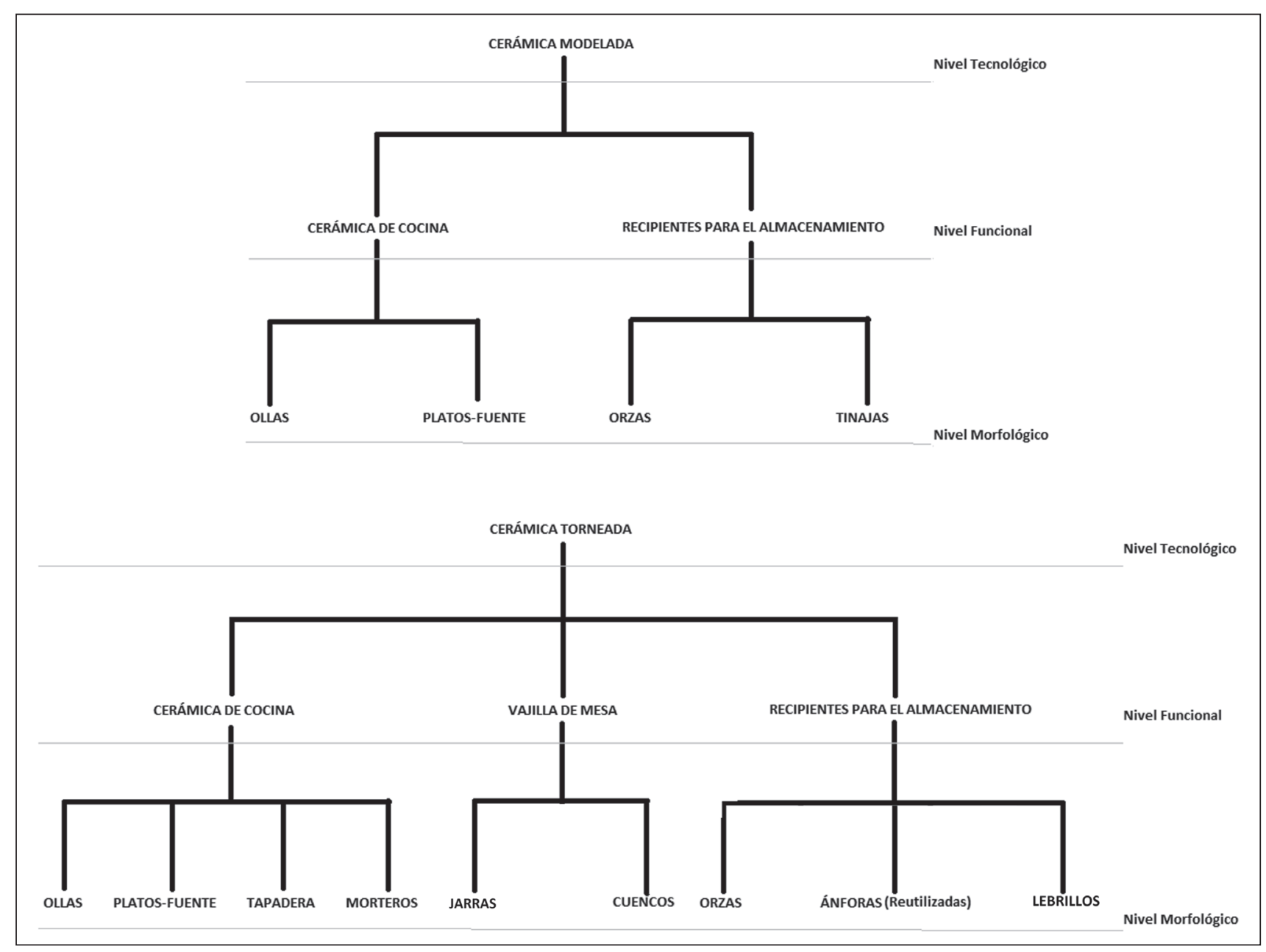

ム Tabla 1. Gráfico-síntesis de propuesta tipológica para la cerámica común y de despensa bajoimperial en el Alto Duero. 


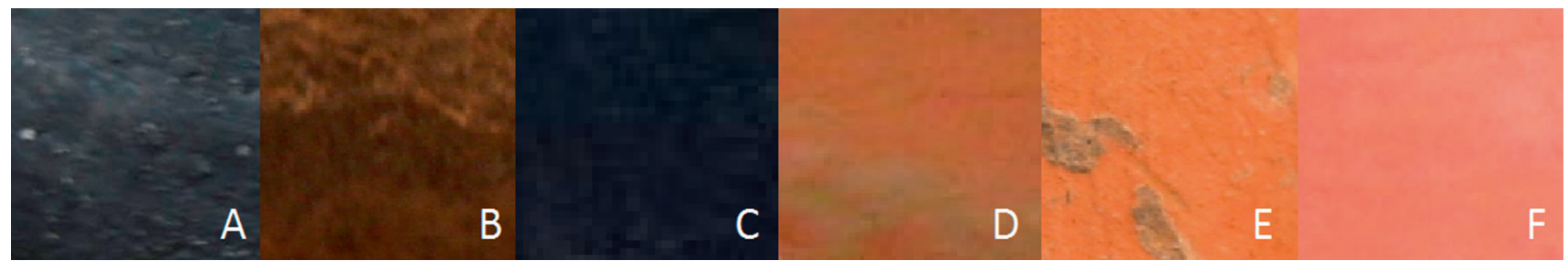

A FiguRa 2. Repertorio cromático de los principales tipos de pastas documentados en las cerámicas objeto de estudio.

\section{PROPUESTA DE CLASIFICACIÓN PARA} LA CERÁMICA COMÚN Y DE DESPENSA
BAJOIMPERIAL EN EL ALTO DUERO

Sobre la base de la aplicación de los criterios metodológicos anteriormente expuestos hemos establecido una serie de tipos. El planteamiento de cada una de las categorías a continuación expuestas recoge la aplicación de criterios correspondientes a todos los niveles de clasificación desarrollados en nuestra propuesta (Figura 2).

\subsection{Cerámicas modeladas}

Dentro de este tipo de producciones incluimos aquellas piezas que han sido realizadas sin la utilización del torno rápido. Algunas de las cerámicas aquí presentadas pudieron haber sido realizadas por medio de la utilización de un torno de mano o torneta. Sin embargo, al no haber podido establecer rasgos tecnológicos precisos que nos permita establecer criterios de discriminación especifica no hemos querido establecer distinciones tipológicas entre las cerámicas modeladas a través de diversas técnicas alfareras como el urdido y las producidas por medio de tornos simples de mano o tornetas. La documentación de diferentes tipos de producciones alfareras modeladas ha supuesto en muchos contextos en torno al 5\% del total de los hallazgos cerámicos registrados. Este tipo de recipientes suelen estar vinculados a talleres de tipo doméstico (Peacock 1982: 17-25). No obstante no hemos de pensar de forma automática que este tipo de productos tienen una procedencia local o como mucho regional (Peacock 1982: 78-79). En este sentido la aplicación de un programa sistemático de analíticas compositivas, tarea aún pendiente, podría revelarnos la existencia de importaciones procedentes de otros centros productores del Mediterráneo occidental.

\subsubsection{Ollas modeladas}

Dentro de esta categoría estarian incluidos una serie de vasos con cuerpo ovoide, base con fondo plano y labio vuelto

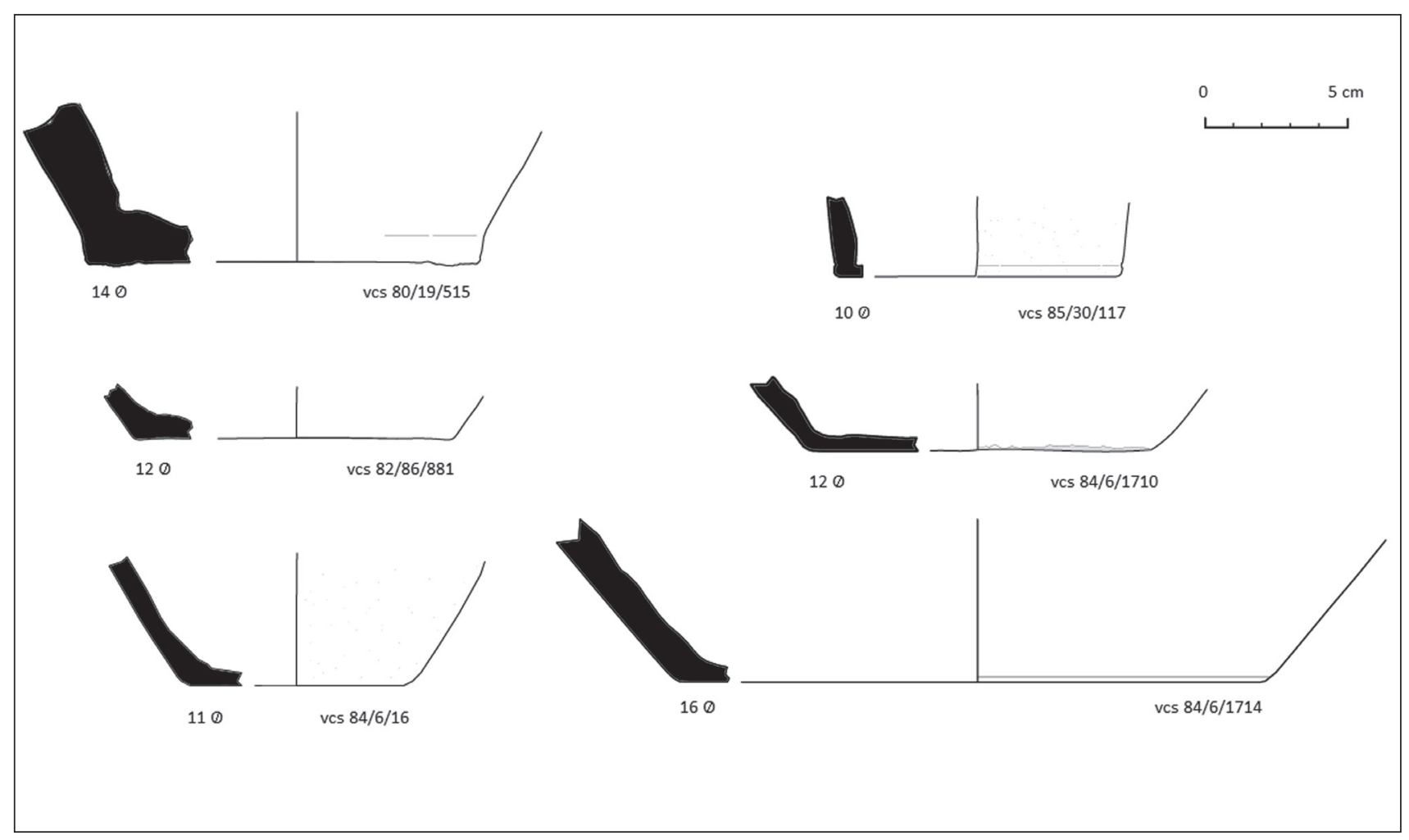

- Figura 3. Fondos de ollas a mano documentados en diversos contextos de las Cuevas de Soria. 


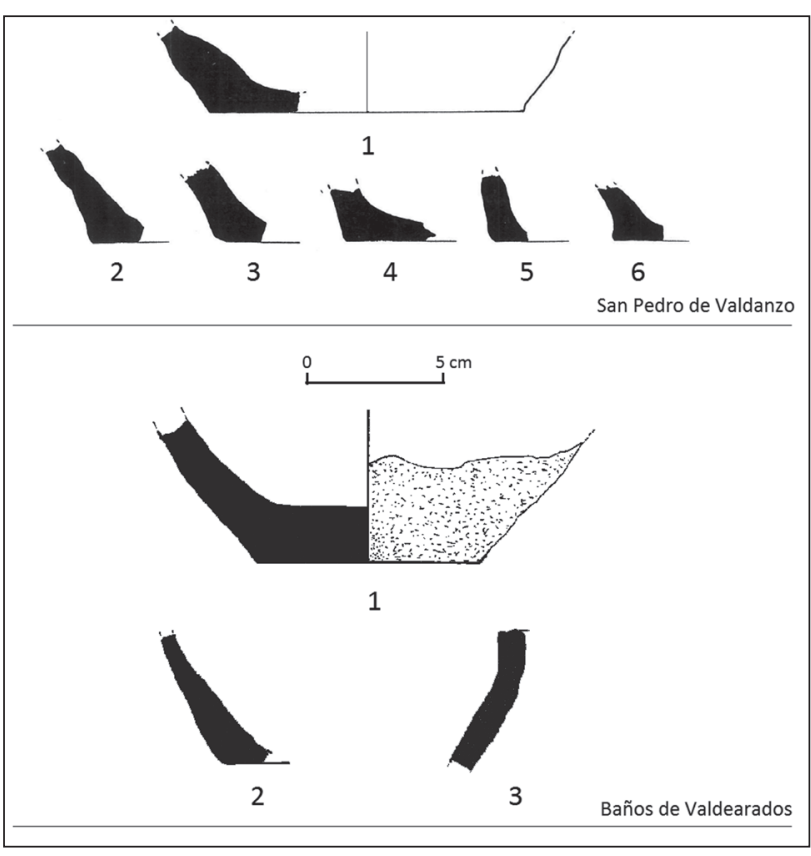

A FiguRa 4. Selección de fragmentos de ollas modeladas procedentes de San Pedro de Valdanzo (Soria) y Baños de Valdearados (Burgos). A partir de Argente Oliver (1979): figs. 22 y 26 y Jimeno Martínez, Argente Oliver y Gómez Santa-Cruz 1988-89: fig. 14.

al exterior que acaba de forma redondeada o bien en un pequeño reborde destinado a encajar una tapadera. Son formas reconocidas ampliamente en la bibliografía precedente (Vegas 1973: tipo 1a; Alarçao 1974: n. ${ }^{\circ} 337,707,873,874$ 887-889; Luezas 1999: forma Mezquíriz 1958 129, 2; Reynolds 1985: formas 7.2 y 7.7, 1993: forma HW 10.8; Martínez Salcedo 2004: tipo 706). En contextos relativamente cercanos al ámbito regional objeto de estudio se pueden documentar varios paralelos tanto formales como técnicos (vid. Fernández Ochoa y Zarzalejos Prieto 1999: grupo 3; Rechin et al. 1996).

Procedentes de los contextos analizados hemos identificado ejemplares adscritos a esta tipología en varios niveles de las Cuevas de Soria (Figura 3), en la villa de Baños de Valdearados (Argente Oliver 1979: n. ${ }^{\circ}$ 58, 168, 470, 530) y también en San Pedro de Valdanzo (Jimeno, Argente y Gómez-Santacruz 1988-89: fig. 15: n. ${ }^{\circ} 18,23,25,122,269,273$ ) (Figura 4).

\subsubsection{Platos-fuente/cazuelas modeladas}

Es un tipo compuesto por recipientes con forma de plato más o menos abierto, de cuerpo tendente a lo cilíndrico, base de fondo plano y borde recto que suele rematarse por medio de labios redondeados. Aunque no es una forma tan común como en el caso de las ollas, también está ampliamente registrada en la bibliografía precedente, sobre todo en determinados ámbitos regionales como el área cantábrica o levante alicantino (Reynolds 1985: forma 4.2; Rechin 1996: Fig. 5 (22, 23); Larrén et al. 2003: tipo 4 (5); Martínez Salcedo 2004: tipos 102 y 105).
En el marco de los contextos analizado tan solo hemos conseguido identificar de forma precisa un ejemplar procedente de la villa de las Cuevas de Soria (Figura 5) (vcs 85/30/1004) así como otro ejemplar procedente de la villa de Baños de Valdearados (Argente Oliver 1979: n. ${ }^{\circ}$ 62) (Figura 6).

\subsubsection{Orzas modeladas}

La diferencia formal entre este tipo y el de determinadas ollas de cocina puede ser muy sutil. En realidad la mayor parte de los indicadores discriminantes se refieren, más que a variantes especificamente morfológicas, a otros elementos compositivos como el tipo de pastas utilizadas (en las cerámicas de cocina a mano el tipo preponderante de pasta es el n. ${ }^{0}$ 1) el volumen, o la presencia de ciertas formas de decoraciones externas. Se trata de vasos de cuerpo ovoide, fondos planos, menos gruesos que los de las ollas, con bordes vueltos hacia afuera y labios redondeados o bífidos. Este tipo cuenta con paralelos formales en varios ámbitos del 0ccidente mediterráneo (Reynolds 1985: forma 9.5; Larrén et al. 2003: forma 12 (1, 2, 4, 6); Martínez Salcedo 2004: tipo 703). Mucho más reducida y aproximada es la documentación de paralelos formales en el ámbito duriense (vid. Illarregui y Puente 2000: Lámina 41).

Entre los contextos objeto de estudio hemos identificado con seguridad dos fondos de orza procedentes de la villa de las Cuevas de Soria (Figura 7) (vcs 82/86/89, $82 / 86 / 825$ y $84 / 6 / 663$ ) y una pieza documentada en la villa de Baños de Valdearados (Figura 8) (Argente Oliver 1979: n. $\left.{ }^{\circ} 831\right)$.

\subsubsection{Tinajas/dolia modeladas}

Son vasijas de gran tamaño, con cuerpo globular, fondo plano y borde vuelto hacia afuera o hacía adentro, normalmente engrosado y a veces enmarcado. La morfología de estos recipientes es similar a la de las orzas y ollas, pero con un tamaño y capacidad superior. Gran parte de estos recipientes presentan decoraciones geométricas practicadas mediante incisión, normalmente en bandas continuas en la franja de los hombros. Algunas de ellas también presentan pequeñas hendiduras en la parte superior de los labios. Se trata de un tipo con múltiples paralelos formales en puntos relativamente distantes del Mediterráneo occidental (Vegas 1973: tipo 49, 117-118 fig. 42; Alarçao 1974 n. 917 lám. LI, n. 996 lám. LXI, 4-5; Luezas Pascual 1999: fig. 10; Macías 1999: tipo 5.6 lám. 27, Martínez Salcedo 2004: tipo 1001; Bonifay 2004: commune type 65, fig. 164: 7) así como en el ámbito del Duero medio (vid. García Merino y Sánchez Simón 2001: Figura 6 (1), Abásolo Álvarez y García Huertas 1993: fig. 69; Centeno, Palomino y Villadangos 2010: Figura 9 n. ${ }^{\circ} 5,6$ y 7 ).

Procedentes de los contextos registrados en las Cuevas de Soria (Figura 9) hemos conseguido identificar un borde 


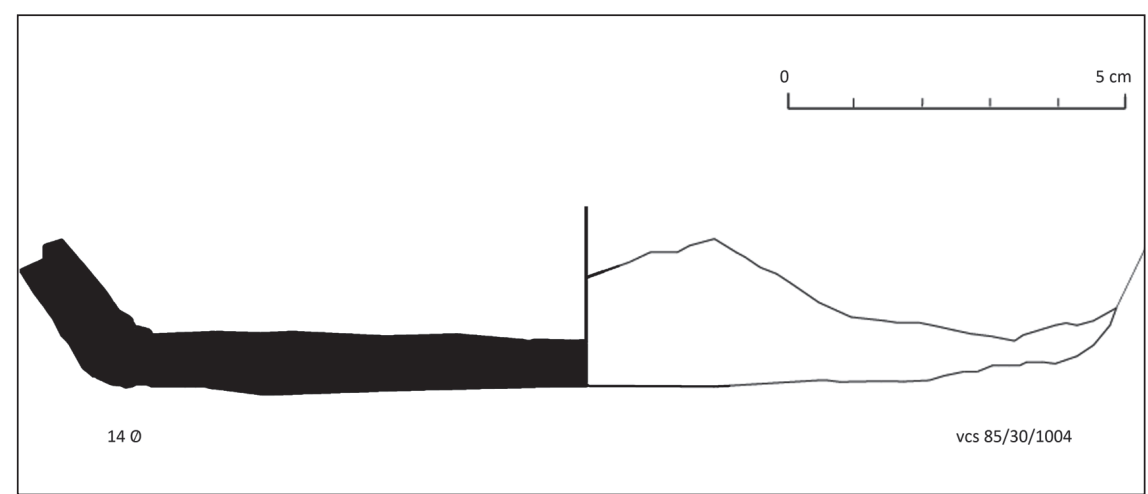

FIGURA 5. Ejemplar de plato-fuente modelado de cocina procedente de las Cuevas de Soria. con el labio vuelto hacia dentro (vcs 85/30/1699) así como los restos de una base (vcs 85/30/57). Procedente de la villa de San Pedro de Valdanzo hemos conseguido identificar un solo fragmento de labio vuelto hacia afuera que parece responder a esta tipología (Jimeno, Argente y Gómez-Santacruz 1988-89: fig. 14, n. ${ }^{4}$ ) así como cuatro piezas más procedentes de la villa de Baños de Valdearados (Argente Oliver 1979: n..$^{774,775,776,944)}$ una de ellas decorada con bandas enmarcadas de reticulado y zigzagueados incisos (Figura 10: Baños de Valdearados n. ${ }^{1}$.

\subsection{Cerámicas torneadas}

En este grupo de clasificación incluimos las tipologías pertenecientes a los recipientes manufacturados mediante el uso de algún tipo de torno rápido o de pie. Dadas las condiciones técnicas y de especialización alfarera requeridas para obtener este tipo de piezas, estas manufacturas suelen asociarse con una escala productiva de tipo taller artesano (Peacock 1892: 28). Este tipo de modelo productivo tiende a especializarse en la producción concentrada de determinadas formas en función de la demanda, que en

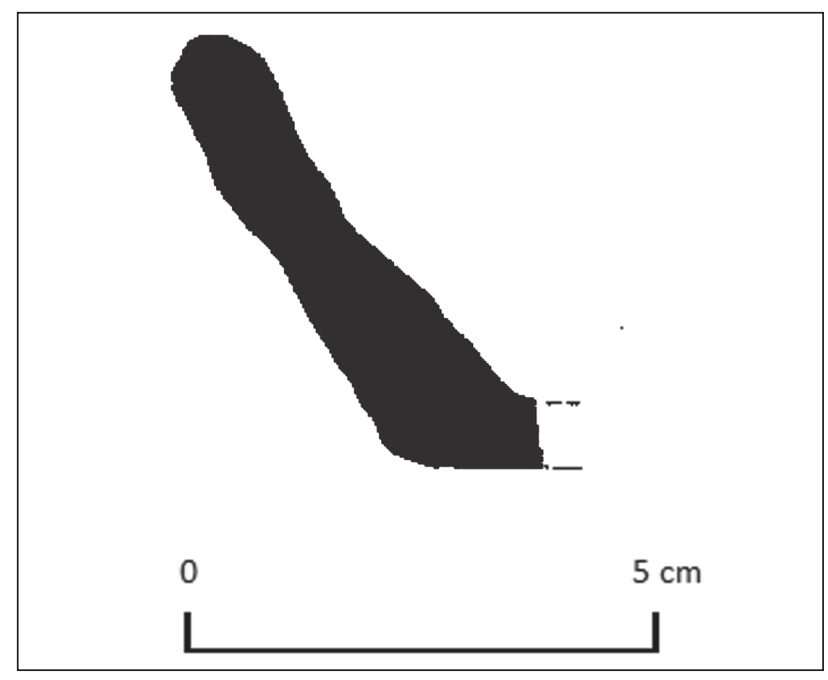

$\Delta$ Figura 6. Fragmento de plato-fuente de cocina modelado prodecente de Baños de Valdearados. A partir de Argente Oliver (1979): fig. 22. determinados casos (por ejemplo, la cerámica de cocina africana vid. Bonifay 2004: 449-458) llegaba a extenderse por todo el Mediterráneo por medio de intrincadas redes de comercio intra- e interprovincial (Reynolds 1993, 1995). En este caso, la estandarización de formas que parece caracterizar este tipo de producciones ha facilitado mucho la tarea de los estudiosos a la hora de establecer la identificación de los diversos tipos en los diversos contextos regionales y locales.

\subsubsection{Ollas torneadas}

A esta categoría pertenecen recipientes de cuerpo ovoideo, base con fondo plano y borde vuelto al exterior con bordes vueltos hacia afuera o achatados (Figura 11: vcs 85/30/2153) con cuellos más o menos estrangulados. Las formas de remate de los labios son muy variadas en función del gesto técnico empleado por el alfarero para terminar las piezas. Entre ellos podemos encontrar bordes bífidos, rehundidos, engrosados o rematados en ángulos agudos. Esta tipología de recipientes cuenta con innumerables paralelos formales en el Mediterráneo occidental (Vegas 1973: variante 1.1 y forma 1 a y forma 3, pp. 12-17, fig. 1-3; forma Celsa 79.70, Di Giovanni 1996: fig. 6 (10-15); Scatozza Höricht 1996: tipo 1 (fig. 2); Luezas Pascual 1999: forma Aguarod I/Varea I y Aguarod III/Varea III fig. 3; Martínez Salcedo 2004: tipos: tipos 707, 710, 711 y 717, Larrén et al. 2003: tipo 10) y en el ámbito duriense (vid. Illarregui y Puente 2000: 128-132, formas 10-18 y Centeno, Palomino y Villadangos 2010: Figura 8, n. $\left.{ }^{\circ} 1-10\right)$. Hemos de notar que, seguramente en competencia con otros productos de cocina típicamente mediterráneos -como los sets campanos de platos de borde bífido/tapadera o los africanos de cacerolas tipo Hayes 197/tapadera- muchas de las producciones hispanas evolucionan desde los tradicionales perfiles en $\mathrm{S}$ hasta la introducción de bordes bífidos para el ajuste de tapaderas.

Hemos documentado abundantes fragmentos de este tipo de producciones en todos los contextos objeto de estudio y en todos ellos es posible documentar ejemplares de los diversos tipos de labios anteriormente reseñados (Figura 11, 13). Se trata pues de un tipo de recipiente am- 


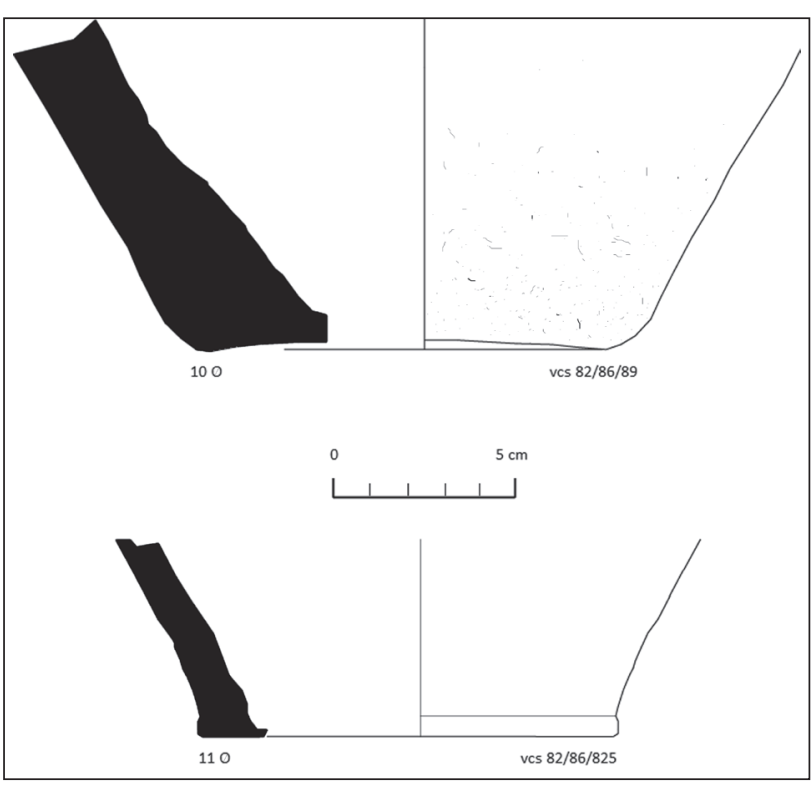

A FiguRA 7. Fondos de orzas de almacenamiento a mano procedentes de dos contextos de la villa romana de las Cuevas de Soria.

pliamente utilizado en las cocinas de los asentamientos del Alto Duero.

\subsubsection{Platos-fuente de cocina torneados}

Son platos de base ${ }^{5}$ plana o ligeramente umbilicada y paredes oblicuas o formando curva con bordes ligeramente entrantes y engrosados. A esta categoria pertenecen los Ilamados platos de borde bífido con engobes interiores (Ilamado genéricamente engobe rojo-pompeyano). Se trata de un tipo de producción normalmente asociada a centros de producción itálicos (Vegas 1973: 43-45, fig. 15.1; Grünewald 1979; Di Giovanni 1996: formas 2110, 2120, 2130, 2140). Ampliamente importados en centros consumidores como el valle del Ebro (Aguarod Otal 1991: 52-53, 65-74) y posteriormente versionados en distintos centros productores de la penínusla Ibérica como los alfares calagurritanos (Luezas Pascual 2001: 74-76 figs. 1-2), en el Pais Vasco (Martínez Salcedo 2004: tipo 101,103, 107, 110) sur de Aquitania (Réchin 1996: fig. 5 n. ${ }^{\circ}$ 17) o en Conimbriga (Alarçao 1974: n. ${ }^{\circ}$ 1034-1035, lám. LVIII) por citar tan solo algunos ejemplos de bien estudiados. Platos muy similares a los documentados en el Alto Duero se han registrado en contextos Pompaelo, junto a cuencos de la forma Drag. 37 de TSHT que ofrecen una adscripción bajoimperial con seguridad (Mezquíriz 1958, fig. 55 n. ${ }^{18}$, fig. 110 n. ${ }^{\circ}$ 98). Su presencia en otros contextos bajoimperiales del valle del Duero también se ha registrado en otros contextos del valle del Duero (García Merino y Sánchez Simón 2001: Figura 6 (4); Illarregui y Puente 2000: Láminas 20-29; Larrén et al. 2003: tipo 4).

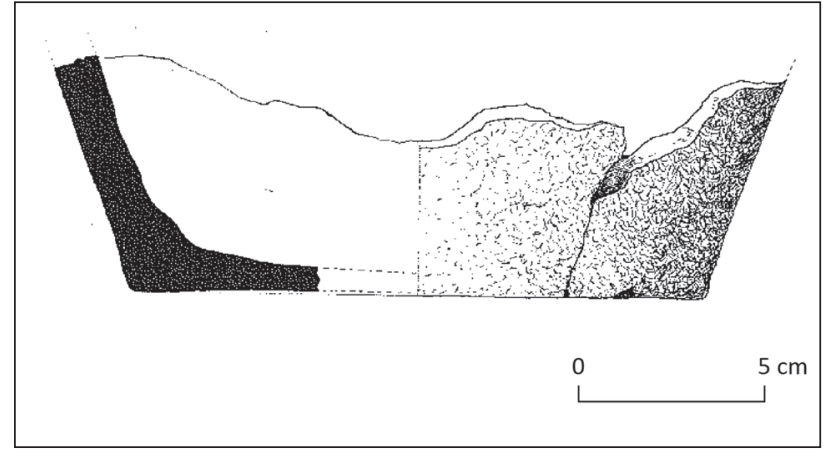

$\Delta$ Figura 8. Fragmento de base de orza modelada procedente de la villa de Baños de Valdearados. A partir de Argente Oliver (1979): fig. 37.

En muchas de estas imitaciones y variantes locales de los llamados platos de engobe rojo-pompeyano es muy común la utilización de componentes micáceos para la aplicación de esta película interior antiadherente. Otra de las características productivas de este tipo de manufacturas es la presencia de ondulados interiores, en forma de círculos concéntricos que puede apreciarse en los interiores de estos recipientes (Figura 14: vcs 82/86/994, 84/6/278, Figura 15: Baños de Valdearados n. ${ }^{\circ}$ 1). Además de los cinco ejemplares completos documentados en el depósito de la Habitación 7 de la Casa de los Plintos (García Merino, Sánchez Simón y Burón Álvarez 2009: fig. 22) se han conseguido identificar tres ejemplares más procedentes de las Cuevas de Soria (Figura 14) (vcs 82/86/865, 82/86/994, 84/6/278) así como el anteriormente citado procedente de Baños de Valdearados (Argente Oliver 1979: n. ${ }^{\circ} 163$ fig. 29).

\subsubsection{Tapaderas y platos-tapadera torneados}

Dentro de esta categoría encontramos fundamentalmente platos de imitación de las formas de tapadera de la cerámica de cocina itálica y africana. Uno de sus rasgos característicos es el ennegrecido de la parte exterior de los labios, producto de su cocción adocenada sin la utilización de fundas y atifles en los hornos de los talleres productores (Hayes 1972: 205; Bonifay 2004: 71). Entre las imitaciones de producciones centromediterráneas se pueden destacar los platos de borde curvo y labio engrosado 0 almendrado (Figura 16: vcs 80/19/sn, 84/6/1708, 85/30/56, 85/30/1003), que recuerdan a los platos de la forma 5/Celsa 75.15 identificados por Aguarod (1991: 118) como platostapadera itálicos o a las mucho más tardías versiones de la forma Hayes 107. El diámetro de muchas de estas piezas, en muchos casos superior a los $20 \mathrm{~cm}$ nos indica que seguramente formaron pareja con los platos-fuentes de inspiración itálica a los que nos hemos referido en el anterior apartado. 


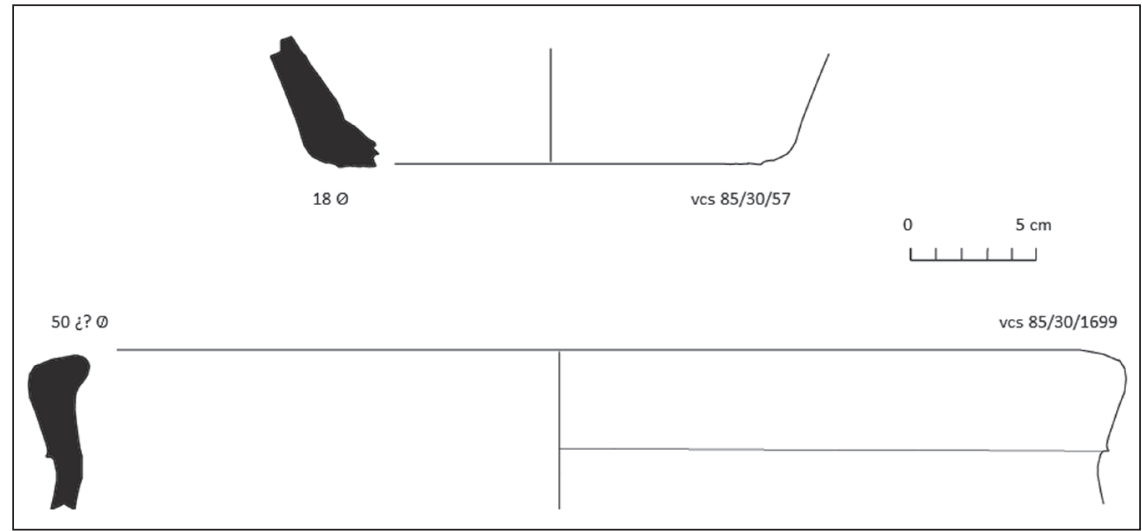

Figura 9. Algunos fragmentos de tinajas/dolia documentados en diversos contextos de la villa romana de las Cuevas de Soria.

Entre los ejemplares documentados en los yacimientos bajoimperiales del Alto Duero hemos registrado una tapadera con un borde (Figura 16: vcs 85/30/2122) que recuerda a la forma culinaire type 13 de Bonifay (2004: 226). El diámetro inferior de esta pieza nos sugiere esta posible filiación africana de la forma, destinada a formar set con un recipiente de cocción con una boca de menor tamaño, del tipo de las cacerolas africanas o las ollas hispanas.

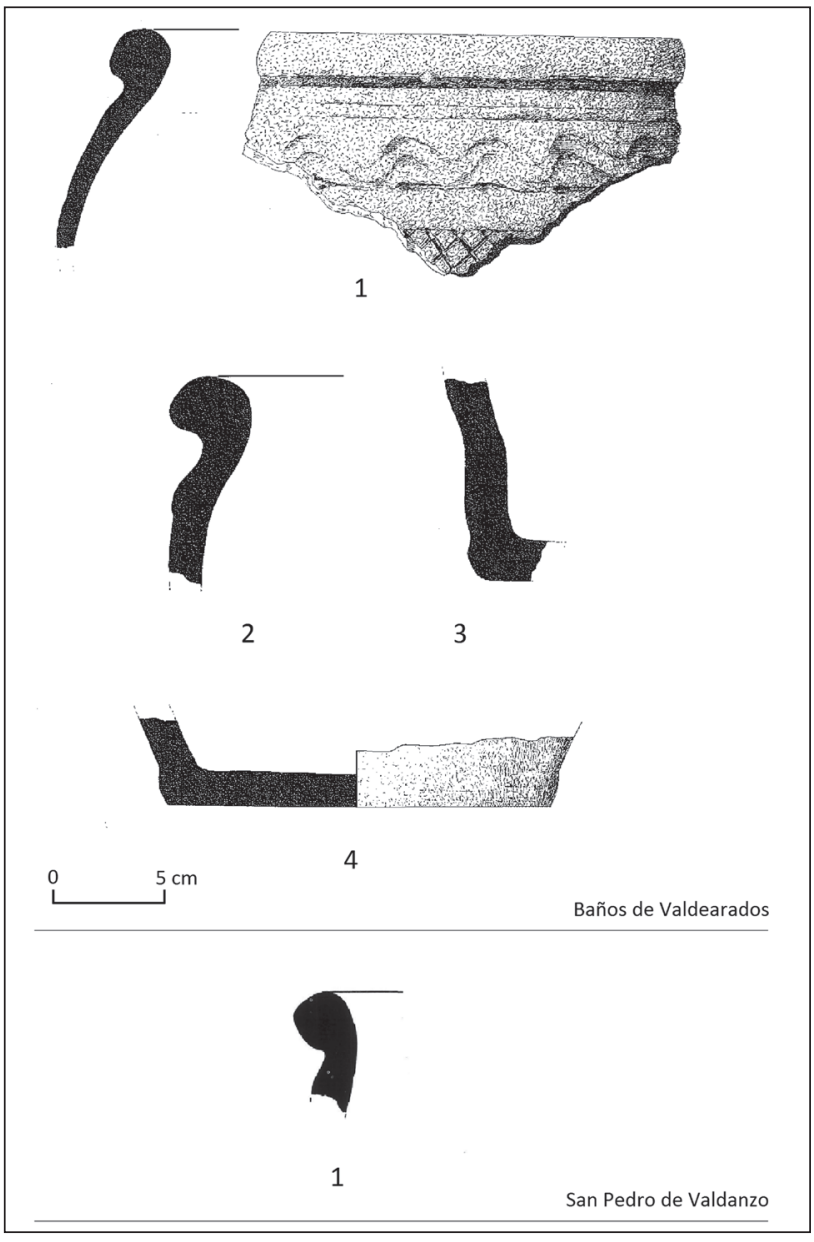

A Figura 10. Fragmentos de tinajas/dolia procedentes de Baños de Valdearados (Burgos) y San Pedro de Valdanzo (Soria). A partir de Argente Oliver (1979): fig. 37 y Jimeno, Argente y Gómez-Santacruz 1988-89: fig. 14.
Dos piezas a las que hemos de insertar dentro de esta categoría son destacan por poseer un diámetro mucho más pequeño en comparación con el resto de las piezas de esta categoría. En concreto hablamos de un fragmento procedente de las Cuevas de Soria (Figura 16: vcs 82/86/799) y de otra pieza completa procedente de la villa de Baños de Valdearados (Argente Oliver 1979: n. 1160 fig. 29). La forma de esta última recuerda a la de la commune type 43 de Bonifay (2004: fig. 153) también documentada en otros contextos de la península Ibérica (forma Arcóbriga 4/Martínez Salcedo 2004: tipo 606). Se trata de piezas que por su tamaño, podrían estar destinadas cubrir jarras o ánforas.

\subsubsection{Morteros}

Este tipo de recipientes, utilizados para el procesado de alimentos y preparación de aditivos, suelen tener un cuerpo curvo e interiores acabados en superficies irregulares (por la inclusión de fragmentos líticos de diversos tamaños en el fondo y paredes internas) para facilitar la disgregación de los alimentos. Las variantes formales en las bases son básicamente tres: 1) fondos planos y macizos, 2) fondos umbilicados y ligeramente elevados, 3) fondos de pie curvo elevado. La mayor parte de estos recipientes pertenecen a diferentes imitaciones de los modelos itálicos del tipo Drumond D2. Producciones de este tipo se han documentado en varias regiones de la península ibérica como el valle del Ebro (Aguarod Otal 1991: 181, Luezas Pascual 2001: 77), Ercavica (Osuna 1976, 127 fig. 43) o el Bajo Aragón (Aguarod Otal 2003: 143-144).

Entre los contextos cerámicos analizados se pueden destacar dos morteros identificados que podrían ser variantes de la forma Drumond D2 procedentes de la Casa de los Plintos (Figura 17: Casa de los Plintos 1) y de San Pedro de Valdanzo (Figura 17: San Pedro de Valdanzo 1). También hemos de destacar una pieza con forma de cuenco sin labio vuelto, que a pesar de poseer las características incrustaciones en la superficie interior del recipiente no responde a las principales tipologías de morteros de procedencia mediterránea (vcs 85/30/1968). No conocemos paralelos formales para este recipiente que tal vez se trate de una variante local de los morteros itálicos. 


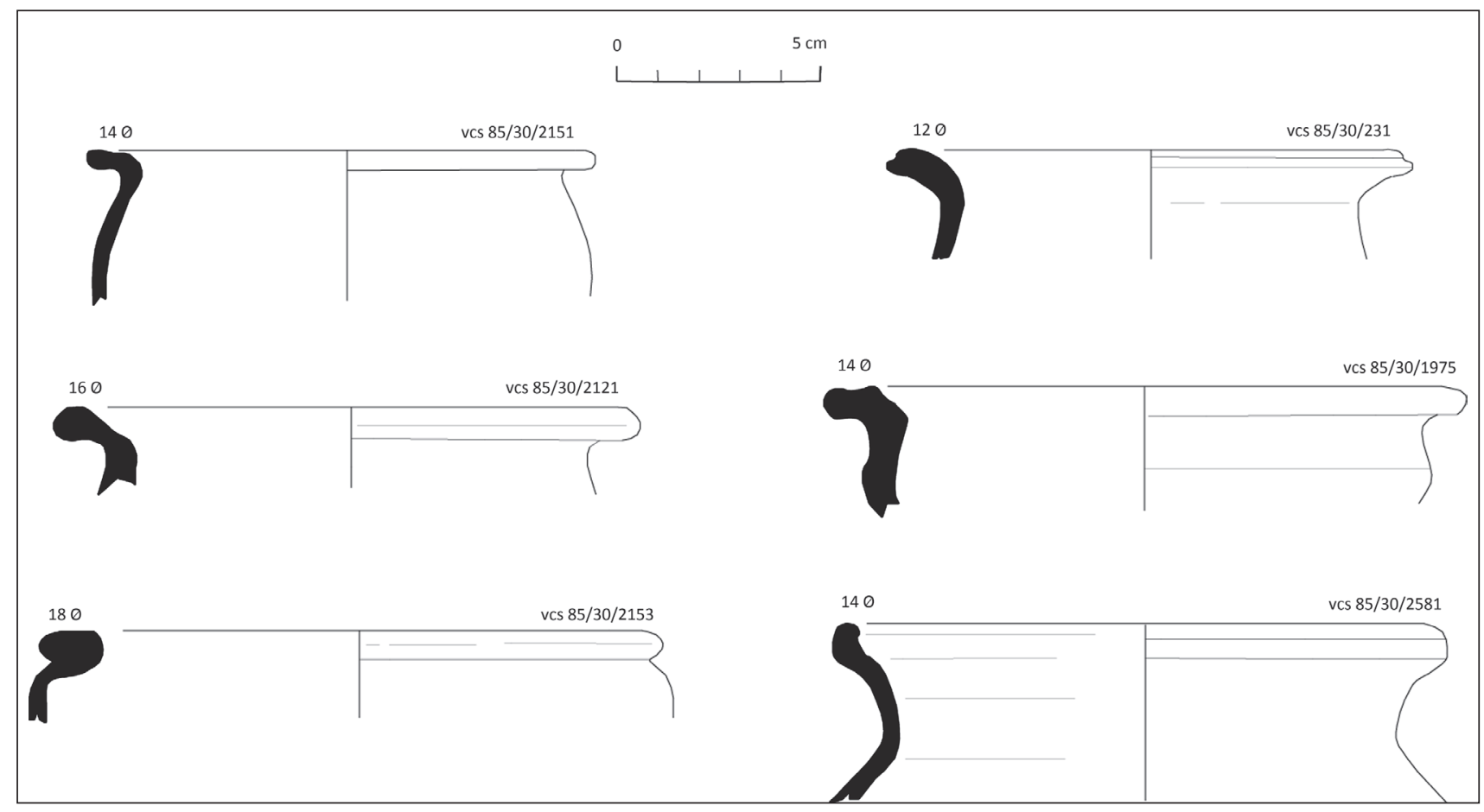

A Figura 11. Bordes de ollas a torno procedentes de varios contextos de la villa de Cuevas de Soria.

\subsubsection{Jarras torneadas}

Dentro de esta categoría incluimos todos aquellos vasos destinados al servicio o transporte de líquidos. Son recipientes de cuerpo globular, paredes finas y cuellos estrechos. En el caso de los vertedores, es frecuente la utilización de asas para controlar el vertido. Las bocas están rematadas por formas verticales con diámetros de boca inferiores casi siempre a los $10 \mathrm{~cm}$. La mayor parte de las bases suelen ser planas o dotadas de un pequeño pie rectangular. Se han documentado varios fragmentos pertenecientes a jarras trilobuladas con bordes redondeados y pico vertedor (vid. Figura 18: vcs 85/30/1329; 85/30/1941) una de las formas con mayor número de paralelos formales en el Mediterráneo occidental (por ejemplo Gasperetti 1996: fig. 6 (45); Coletti y Pavolini 1996: fig. 6 (1-3); Martínez Salcedo 2004: tipo 803).

Entre los abundantes ejemplares documentados entre los yacimientos estudiados se pueden distinguir tres subgrupos con respecto a la forma de los bordes: 1) tipo labio con perfil biglobular (Figura 18: vcs 82/86/987; Argente Oliver 1979: n. 717 fig. 28, n. 1919 fig. 67). 2) tipo labio ligeramente vuelto hacía fuera y remate redondeado (Figura 18: vcs 80/19/519, 82/86/752, 85/30/987; Jimeno, Argente y Gómez-Santacruz 1988-89: n. ${ }^{\circ} 168$ fig. 13) 3) tipo labio vuelto hacía fuera y engrosado o almendrado (Figura 18: vcs 80/19/522). Otro de los rasgos característicos de este tipo de recipientes es la presencia de decoraciones pintadas, normalmente monocromas y dispuestas de líneas paralelas.

\subsubsection{Cuencos torneados}

Estos recipientes para el servicio de mesa suelen tener bocas abiertas y estructura semiesférica. Los bordes suelen ser curvos con labios vueltos al interior o ligeramente exvasados, engrosados y de contorno redondeado.

Existe una variante formal que consiste en recipientes de cuerpo troncocónico (Figura 19: vcs 85/30/1357) con paralelos documentados en contextos tardorromanos (siglo IV- mediados del V d. C.) del norte peninsular (Martínez Salcedo 2004: 136).

De forma genérica se puede afirmar que es una de los tipos más ampliamente registrados en los repertorios de cerámica común del ámbito hispano (Larrén et al. 2003: tipo 2 (1); Luezas Pascual 1995: 188; Martínez Salcedo 2004: tipos 301-319; Peinado Espinosa 2010: tipo COM-RO-BET 2.4 -fig. 4.8-). Es un tipo de recipiente cuya producción estaba destinada a competir con otras formas similares de TSHT (Cuencos de las formas Ritt. 8, Drag. 24/25, Drag. 37) así como con recipientes origen africano (Hayes 14-17; Bonifay 2004: type 10 pg. 157) o con las versiones imitaciones locales de la sigillata (Juan Tovar y Blanco García 1997).

\subsubsection{Orzas torneadas}

Las variantes torneadas de esta categoria formal suelen ser recipientes de cuerpo globular y bases planas o ligeramente elevadas, al igual que las formas modeladas. Las mayores diferencias entre este tipo de recipientes con respecto a las ollas de cocina, además de las huellas de exposición al fuego y la presencia de componentes refractarios son las 


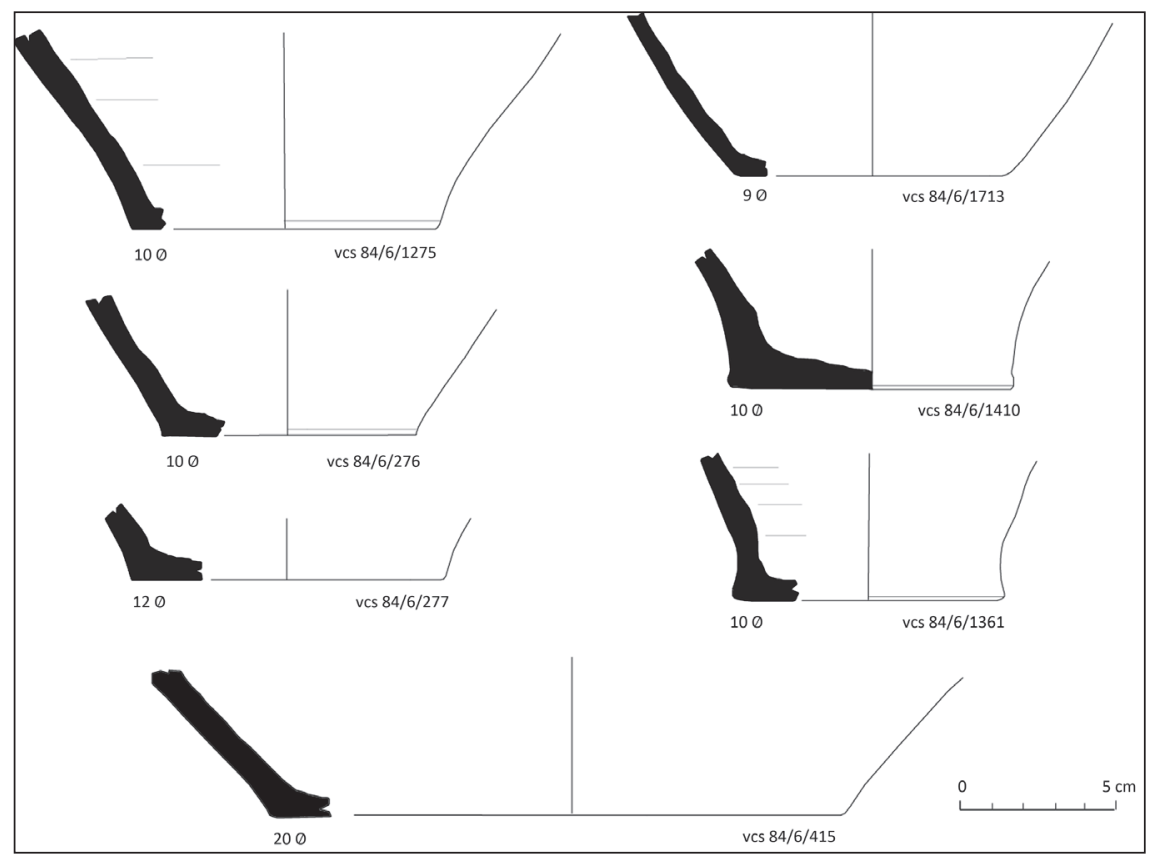

4 Figura 12. Fondos de ollas torneadas procedentes de la villa de las Cuevas de Soria.

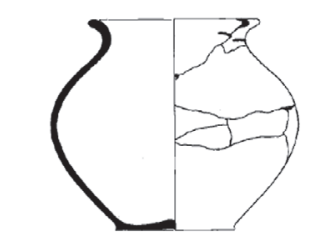

1

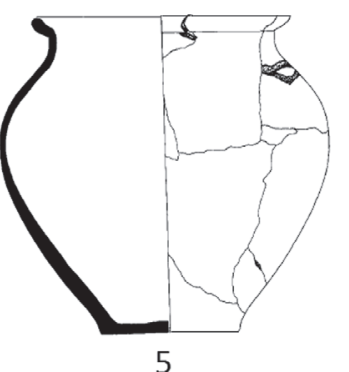

5

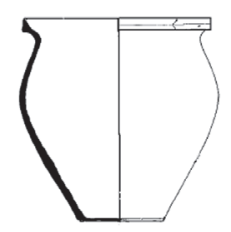

2

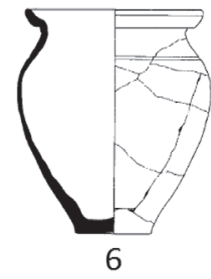

6

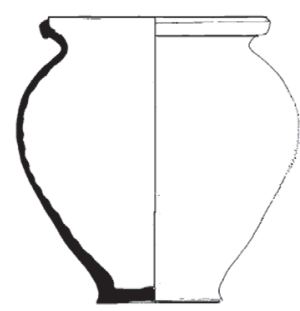

3

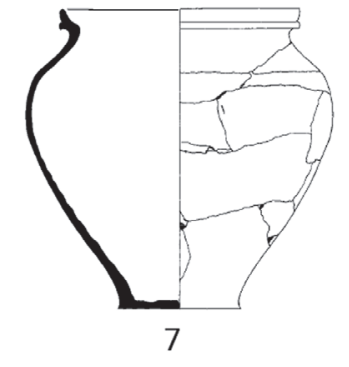

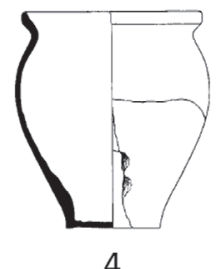

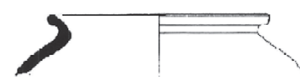

1

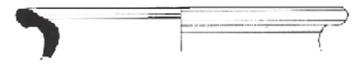

2

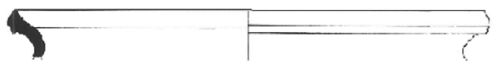

4

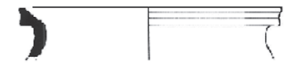

3

San Pedro de Valdanzo

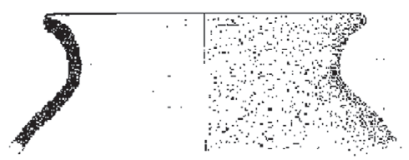

1

Baños de Valdearados

A Figura 13. Selección de ollas torneadas procedentes de contextos cerámicos del Alto Duero. A partir de García Merino, Sánchez Simón y Burón Álvarez 2009: fig. 17 y 18; Jimeno, Argente y Gómez 1988-89: fig. 12; Argente 1979: n. ${ }^{0} 74$ fig. 22). 


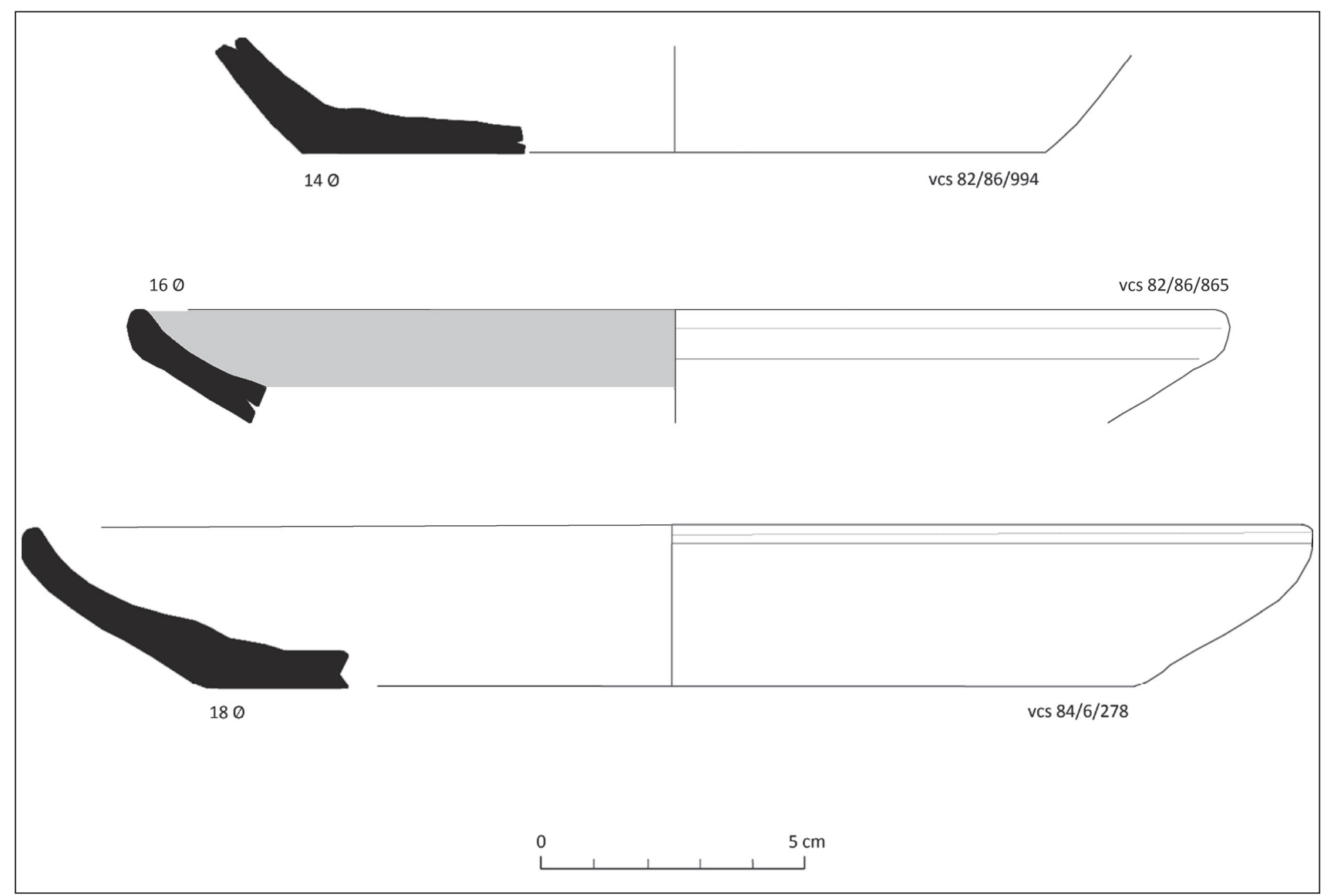

\ FIgura 14. Platos-fuente de cocina torneada procedentes de los contextos registrados en la villa romana de las Cuevas de Soria.

mencionadas bases de menor grosor y la abundante presencia de decoraciones aplicadas en las superficies exteriores.

Otro de los rasgos formales, ampliamente documentado en los recipientes en el ámbito altoduriense, es la presencia de bases con pies redondeados (vid. Figura 20: vcs $85 / 30 / 223,85 / 30 / 66$ ) y fondos umbilicados. Este rasgo se documenta en otros paralelos formales del valle del Duero en época tardoantigua (Larrén et al. 2003: tipo 11 (2), fig. 9).

\subsection{8 Ánforas (reutilizadas)}

Esta categoria introduce una excepción con respecto a la aplicación del concepto de "Intended Vessel Function" que hemos desarrollado en este trabajo. En realidad con esta tipología nos referimos a todas aquellas ánforas que, en virtud de su reutilización en contextos domésticos, pueden incluirse dentro del tipo $B$ de reutilizaciones de vasos cerámicos romanos propuesto por J. T. Peña (2007: 10, 123-133).

Entre los contextos registrados se han documentado varios ejemplares de recipientes anfóricos que sirven para documentar este tipo de reutilización en la región. En la Casa del Acueducto de Tiermes se documentaron varios fragmentos anfóricos. Dos de ellas pudieron identificarse como ánforas tarraconense correspondientes a las formas Beltrán II y IV (Argente Oliver et al. 1994: fig. 47). En la villa de San Pedro de Valdanzo hemos documentado un fragmento de borde de ánfora (Jimeno Martínez, Argente Oliver y GómezSantacruz 1988-89: fig. 14 n. ${ }^{\circ}$ 238) que podría corresponder a un ejemplar del tipo Keay XVI A, una forma tardoantigua de origen bético normalmente elaborada para la exportación de salazones. En el depósito de la habitación n. ${ }^{\circ} 7$ de la Casa de los Plintos de Uxama se identificaron varios fragmentos pertenecientes a tres ejemplares. Uno de ellos se corresponde con la forma Dressel 2/4 de ánforas tarraconenses. Otro ejemplar parece perteneciente a un ánfora de salazón (García Merino, Sánchez Simón y Burón Álvarez 2009: fig 19: $n .{ }^{\circ}$ 2) y un tercero es indeterminado aunque parece corresponder a un ánfora bética de tipo oleario (Garcia Merino, Sánchez Simón y Burón Álvarez 2009: 239). La presencia de este tipo de ejemplares en un contexto cerrado del siglo III d. C. parece indicar una perduración cronológica de su uso producto de su incorporación al repertorio de la despensa doméstica.

\subsubsection{Lebrillos}

Es un tipo de forma cuya funcionalidad no está suficientemente definida, a pesar de que nosotros hemos considerado incluirla dentro de los recipientes destinados a diversos usos domésticos. Son recipientes de forma cilíndrica con una morfología similar a la de los kalathos de la cerámica protohistórica peninsular. Se pueden documentar 


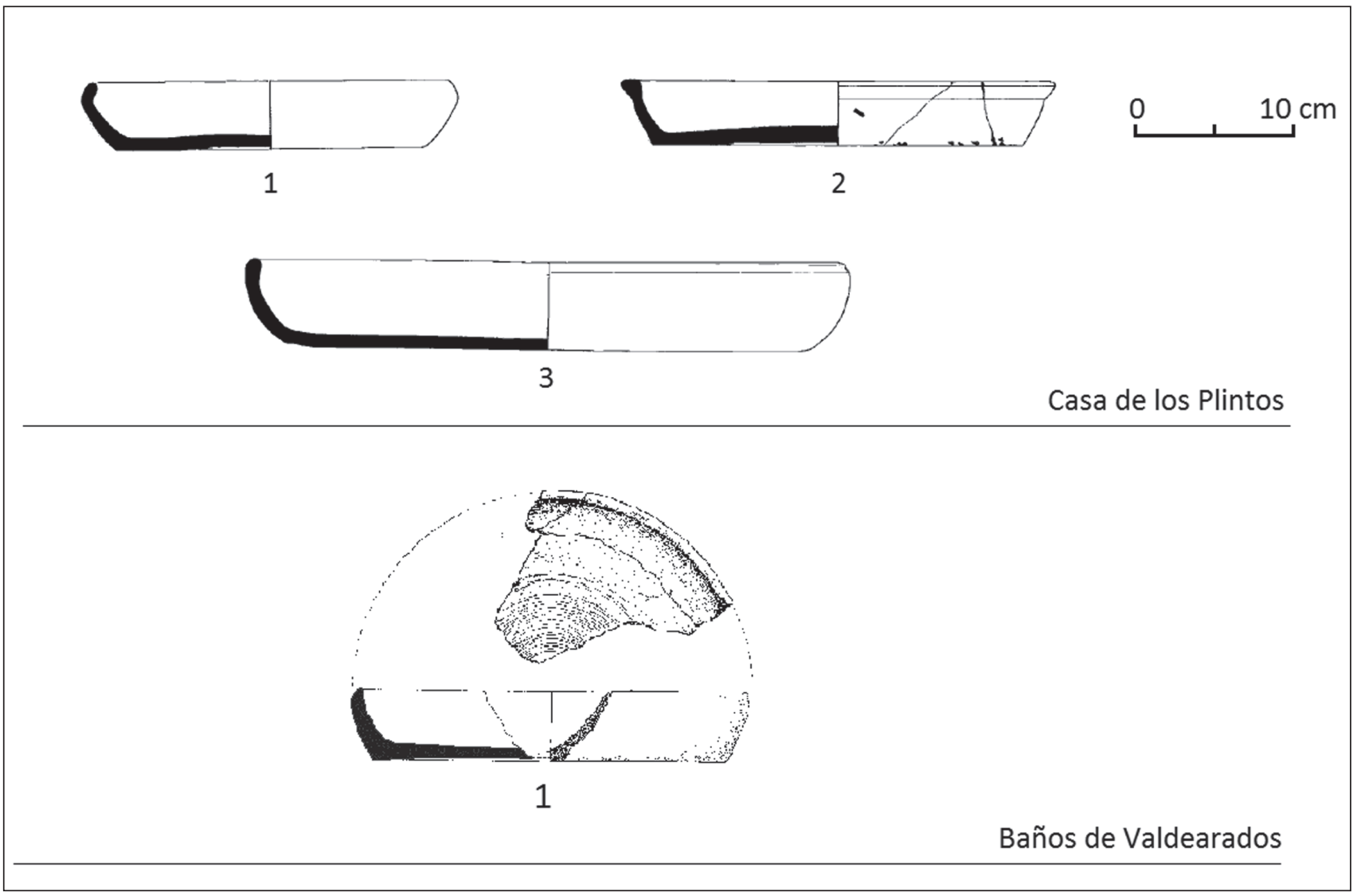

$\Delta$ Figura 15. Platos-fuentes procedentes del depósito de la Habitación n.$^{\circ} 7$ de la Casa de los Plintos y Baños de Valdearados. A partir de García Merino, Sánchez Simón y Burón Álvarez 2009: Fig. 17 (3, 4, 5) y Argente 1979: fig. 29 (163).

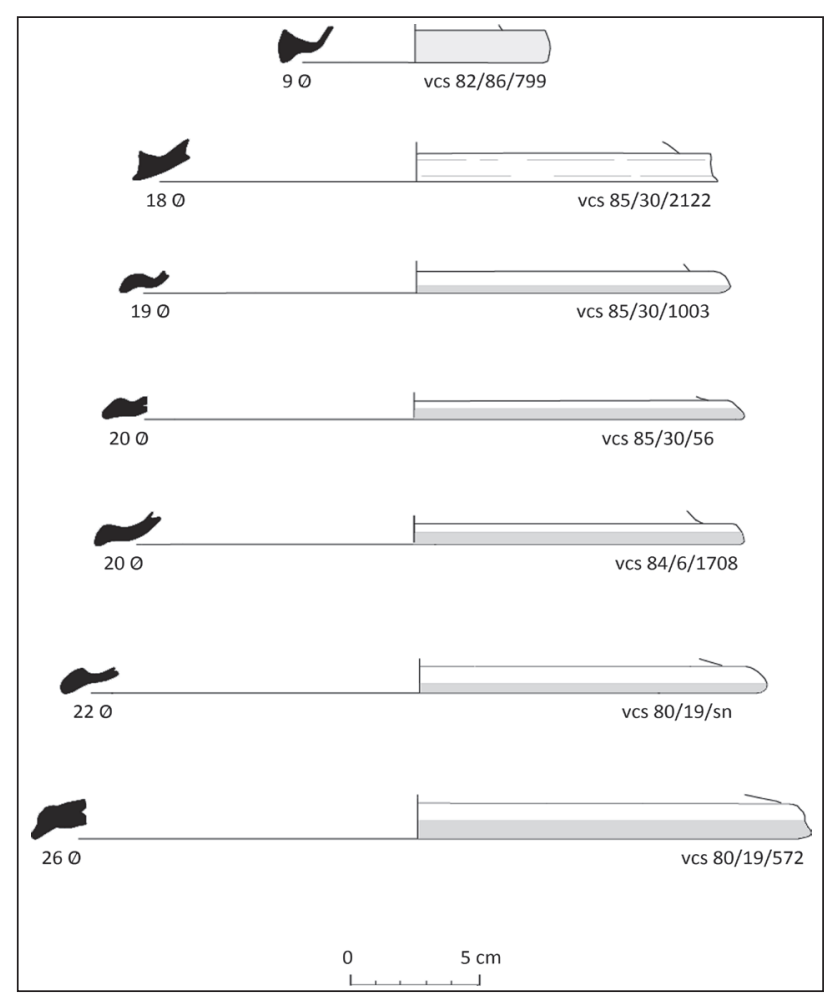

$\Delta$ Figura 16. Fragmentos de platos tapadera de inspiración mediterránea procedente de los contextos cerámicos registrados en las Cuevas de Soria. distintos tipo de paralelos formales, ciertamente poco precisos, en diversos ámbitos del mediterráneo occidental y central (vid. Vegas 1973: tipo 12; Luezas Pascual 1999: Fig. 6; Martinez Salcedo 2004: tipo 1301-1302; Peinado Espinosa 2010: tipo COM-RO-BET 4.3 fig. 4.16; Bonifay 2004: commune type 21,22 ).

Hemos conseguido identificar un único fragmento de base con fondo umbilicado de uno de estos recipientes entre los contextos de la villa de las Cuevas de Soria (vid. Figura 21) aunque no hemos conseguido identificar paralelos formales cercanos entre los lebrillos publicados en contextos imperiales del ámbito duriense (vid. Carretero Vaquero 2000: 14.2.11 Figura 369 n. ${ }^{\circ}$ 251; Centeno, Palomino y Villadangos 2010: Figura 9 n. ${ }^{\circ} 3$ y 4).

\section{APUNTES FINALES: LA CERÁMICA COMÚN BAJOIMPERIAL ALTO DURIENSE EN SU CONTEXTO HISTÓRICO}

Como hemos afirmado al principio de este trabajo creemos que el estudio de las producciones de la llamada cerámica común romana debe trascender el registro de nuevas referencias cronotipológicas para abrirse a un estudio contextualizado de los repertorios. Solamente de esta forma 


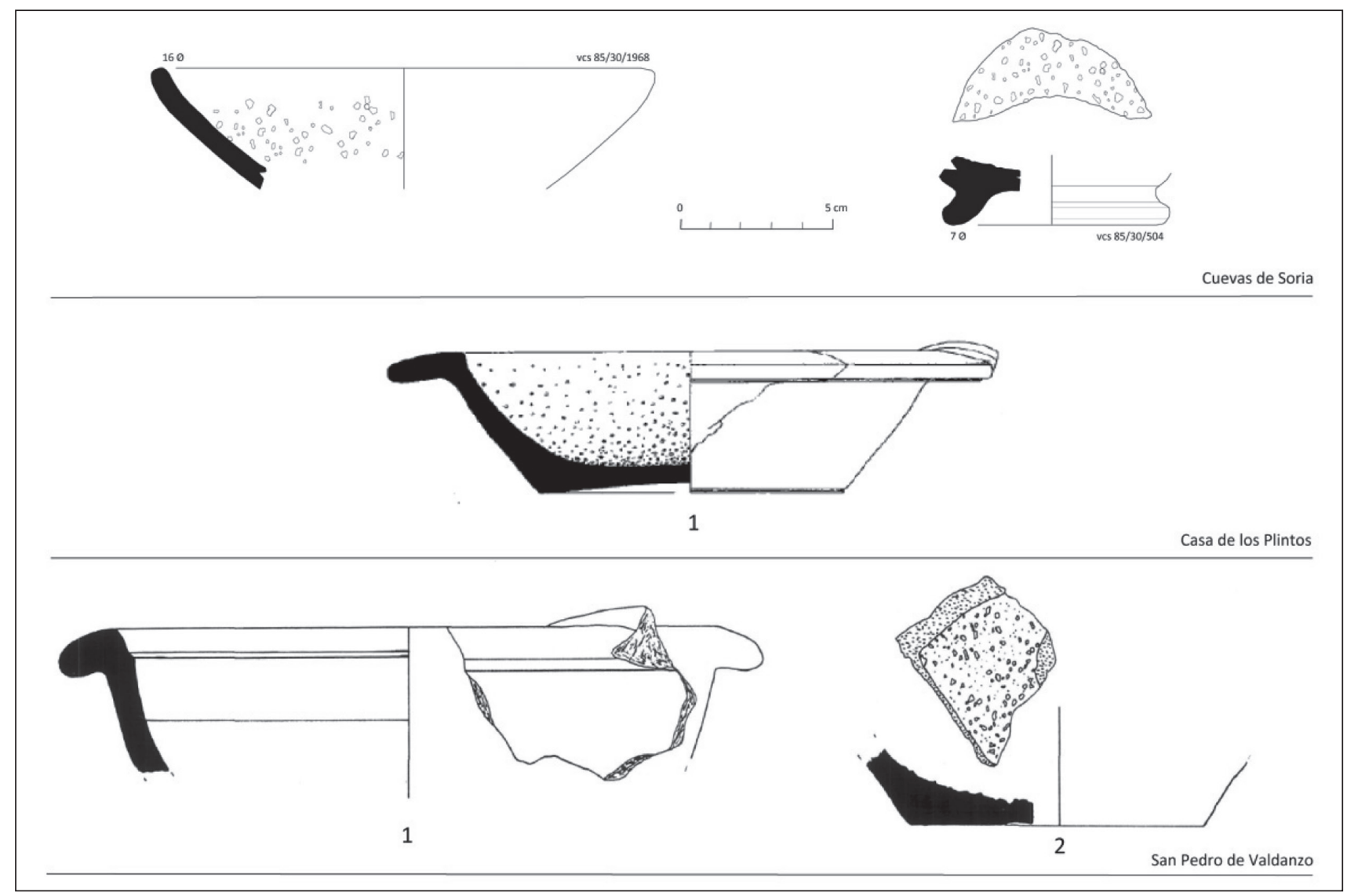

- Figura 17. Morteros procedentes de contextos cerámicos registrados en las Cuevas de Soria, en la Casa de los Plintos, a partir de García Merino, Sánchez Simón y Burón Álvarez 2009: Fig. 17 (8) y de la villa de San Pedro de Valdanzo, a partir de Jimeno, Argente y Gómez-Santacruz 1988-89: fig. 14).

podremos empezar a vislumbrar las posibilidades del estudio de este tipo de materiales para ilustrar diversos aspectos sociales y económicos de las comunidades que las produjeron, consumieron y abandonaron.

Desde una perspectiva contextual podemos apreciar que, en lo que respecta a las producciones objeto de estudio, las dos formas que se pueden adscribir de un modo más preciso a un horizonte bajoimperial (mediados del siglo III d. c.- comienzos del siglo $\mathrm{V}$ d. C.) diferenciado de contextos "visigóticos" (a partir de mediados del siglo $\mathrm{V} \mathrm{d}$. C.) son las ollas toneadas con labios bífidos o rehundidos (Forma 5.2.1) y los platos y fuentes de imitación de producciones de engobe interno rojopompeyano (Forma 5.2.2). Estos productos, presentes en todos los contextos de las villae y domus bajoimperiales presentados y en otros contextos del Duero medio como Relea (Juan Tovar, Pérez González y Fernández Ibáñez 1995: Figura 6), desaparacen de los repertorios formales conocidos para los pocos estudios centrados en esta región de la Meseta o en zonas muy próximas (vid. Juan Tovar y Blanco García 1997; Blanco García 2003: 149-157; Larrén et al. 2003).

Este mismo fenómeno de presencia generalizada en época bajoimperial y desaparición en contextos de mediados del siglo $\mathrm{V} d$. $C$. ha sido también registrado en los trabajos de A. Vigil-Escalera (2007: Figuras 3 y 4) del ám- bito de la comunidad de Madrid. Estos cambios parecen ser un reflejo de la evolución histórica en los procesos de cocinado de alimentos registrados entre ambos periodos. De este modo, las ollas con labios dispuestos para la recepción de tapaderas y los platos de engobe rojo interno podrian reflejar la presencia de gustos más cercanos a las tradiciones romanas. La presencia mayoritaria de este tipo de ollas y platos de cocina en los repertorios altodurienses supuso una exitosa adaptación de algunas características técnicas y formales registradas en los sets de cocina itálica y africana en las cocinas locales. La escasa presencia juegos de cocina (cacerola de fondo globular/tapaderas) de importación mediterránea entre los contextos domésticos bajoimperiales del área nos indica la implantación de las ollas torneadas (Forma 5.2.1) como el recipiente de cocina más utilizado en dicho periodo. En este mismo sentido, la presencia de elementos de cocina como las ollas modeladas con labios rectos y planos, que entroncan claramente con elementos de cocina registrados en contextos de la Edad del Hierro, nos remiten a una cierta perduración de diferentes modos de cocción de los alimentos.

La evolución de los porcentajes relativos de este tipo de elementos en los contextos materiales disponibles podría servir para registrar patrones de cambio en los gustos cu- 


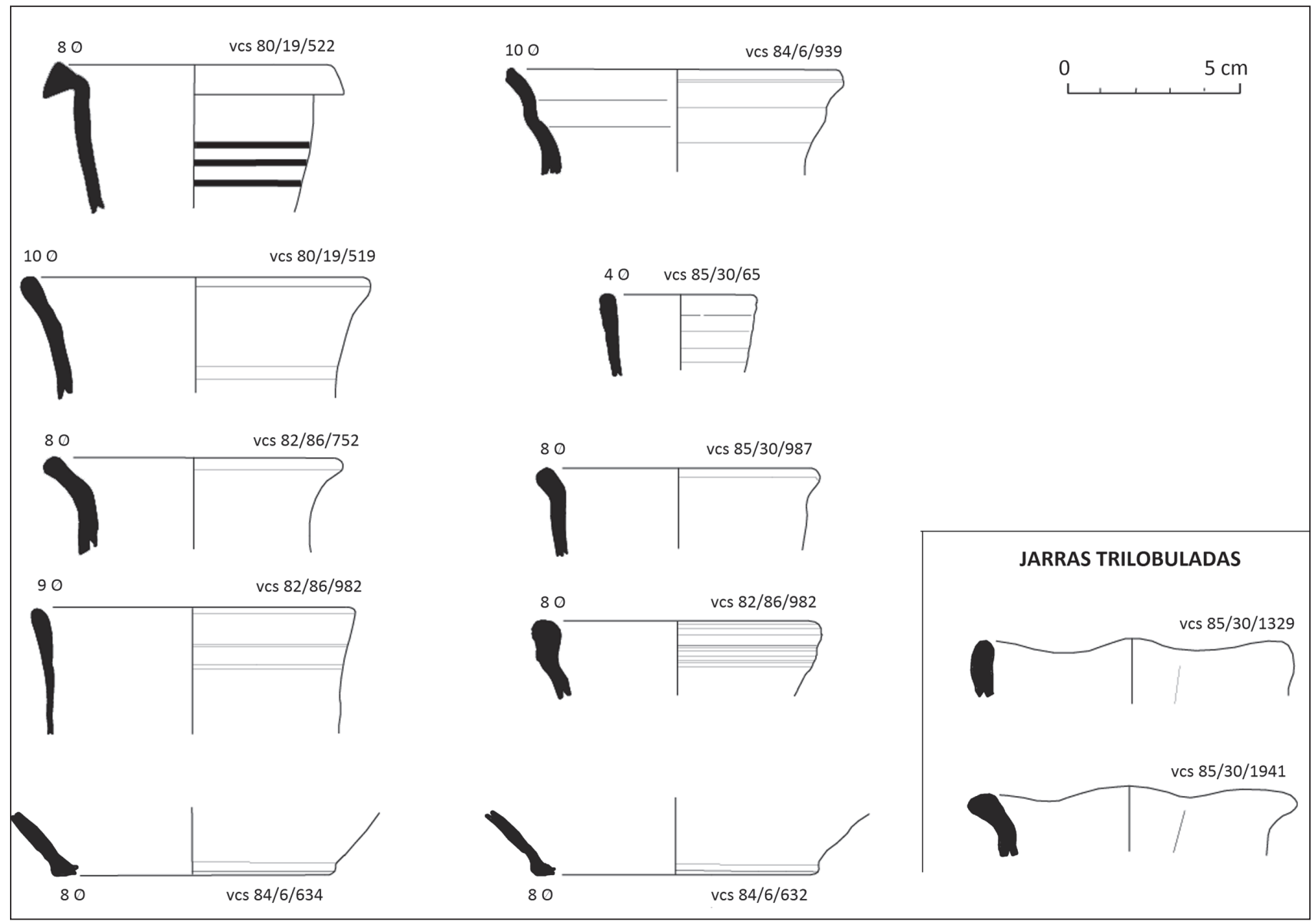

A Figura 18. Selección de fragmentos de jarras documentadas entre los contextos cerámicos de la villa de las Cuevas de Soria.

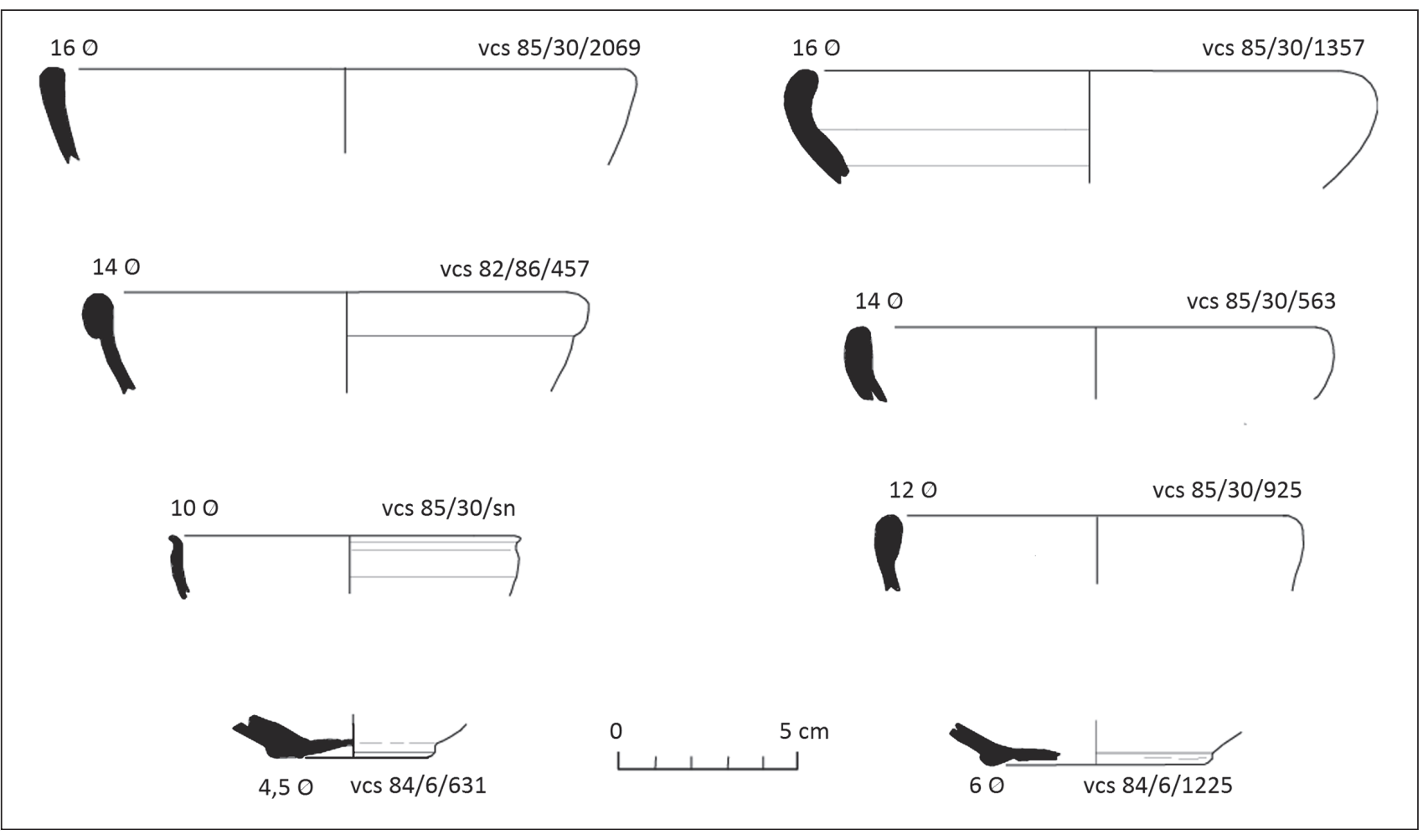

A Figura 19. Selección de fragmentos de cuencos torneados documentadas entre los contextos cerámicos de la villa de las Cuevas de Soria. 


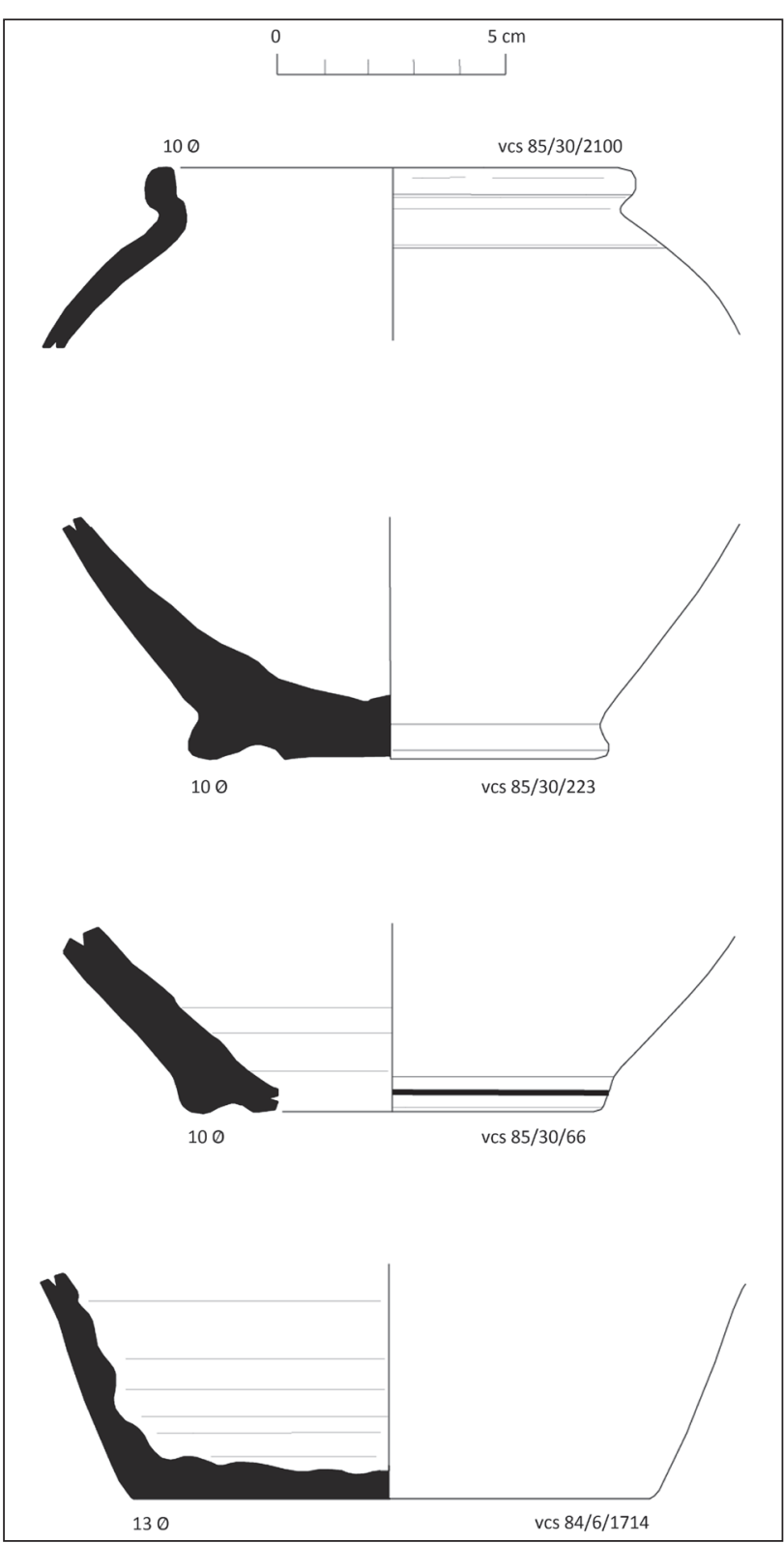

$\Delta$ Figura 20. Selección de fragmentos de orzas torneadas documentadas entre los contextos cerámicos de la villa de las Cuevas de Soria.

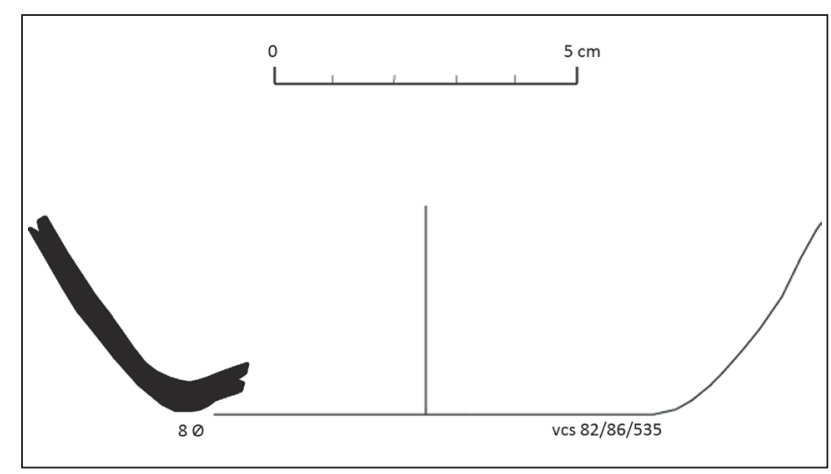

4 Figura 21. Fragmento de base de lebrillo procedente de la villa de Cuevas de Soria. linarios de los habitantes de la región entre en los últimos siglos de implantación del sistema imperial romano.

Pero estos cambios no se refieren únicamente a los repertorios de cocina. El estudio de determinados rasgos formales de la vajilla de mesa también nos sirve para identificar ciertos rasgos asociados a un horizonte bajoimperial. La presencia mayoritaria de formas de cuencos torneados (Forma 5.2.6) con bordes curvos, perfil convexo y tendencia al engrosamiento de los labios podría ser identificado como un rasgo diferenciador de contextos bajoimperiales presentes en los contextos analizados, así como en otras villae del valle del Duero (García Merino y Sánchez Simón 2001: Figura 10 n. ${ }^{0} 19$; Illarregui y Puente 2000: Lámina 17 n. ${ }^{\circ}$ 9. 5). A partir de la segunda mitad del siglo $\mathrm{V} d$. C., la sustitución de este tipo de recipientes de mesa por diversas variedades de cuencos carenados de perfil convexo se ha registrado en todo el valle del Duero (vid. Juan Tovar y Blanco García 1997: Figura 4; Larrén et al. 2003: Figura 3: n. $\left.{ }^{\circ} 4-15\right)$ y en el ámbito madrileño (Vigil-Escalera 2003: Figura 1; Vigil-Escalera 2007: Figura 5). Otro de los rasgos morfológicos diferenciadores es la tendencia al ensanchamiento de los diámetros de boca (Vigil-Escalera 2003: 377) que se registra en este último tipo de cuencos carenados a partir de la segunda mitad del siglo V d. C. (comparar Figura 19 con Juan Tovar y Blanco García 1997: Figura 4 y Vigil-Escalera 2007: Figura 5).

Estas variaciones morfológicas son reflejo de los diversos gestos técnicos empleados en el torneado de estos recipientes. Los bordes con perfil cóncavo y diámetros más estrechos de boca son producto de tornos rápidos o de pie que permiten una mayor precisión a la hora de levantar este tipo de formas cerámicas que requieren gestos técnicos en los que se hace preciso la utilización continua de ambas manos durante el torneado y un giro del torno más homogéneo (Kirchner 2007: 224). En cambio los perfiles carenados con bocas de diámetros en torno a los $20 \mathrm{~cm}$ (similares a los de muchas de las formas registradas durante el Hierro I de la región vid. Romero Carnicero 1991: 132-170) y tendencia a rematar los labios con secciones ligeramente triangulares reflejan gestos técnicos propios del modelado de cerámicas con tornos lentos.

Sin embargo, como hemos afirmado a lo largo de nuestra propuesta de clasificación, la presencia -en porcentajes relativos reducidos- de diversos productos modelados supone que la utilización de diversas opciones tecnológicas no puede asociarse de forma automática como un rasgo excluyente a la hora de definir adscripciones cronológicas. En este sentido se puede afirmar que el análisis exhaustivo de contextos cerámicos documentados en yacimientos bajoimperiales del Alto Duero refleja la convivencia de diversos procesos tecnológicos. La evolución de determinadas formas de manufactura cerámica, y su reflejo cuantitativo en el contexto arqueológico de los asentamientos analizados, se debe no tanto a procesos de "retroceso" o "avance" tec- 
nológico como a la evolución histórica de las condiciones de organización productiva de los grupos humanos estudiados.

La reconstrucción de los diversas cadenas operativas de producción alfarera reconocibles en los contextos analizados nos permitirá obtener una imagen más certera (y seguramente más compleja) de las formas de organización social de la Economía bajoimperial. La aplicación de un programa sistemático de analíticas arqueométricas y, sobre todo, la adopción de una metodología tendente al análisis y publicación de contextos de un modo exhaustivo servirá sin duda para avanzar en un conocimiento más completo de los circuitos económicos vinculados a la producción de cerámica en el Alto Duero durante la Antigüedad. Con este objetivo en el horizonte, el presente estudio únicamente constituye una aproximación inicial para facilitar el desarrollo de programas de investigación que consideren el análisis de este tipo de manufacturas cerámicas como documento para la reconstrucción de las condiciones socioeconómicas de aquellos grupos humanos que las produjeron, distribuyeron y utilizaron. •

\section{BIBLIOGRAFÍA}

Abásolo Álvarez, J. L. y García Huerta, R. 1993: Excavaciones en Sasamón, EAE 164, Madrid.

ADAmS, W. Y. y AdAms, E. W. 1991: Archaeological typology and practical reality: a dialectical approach to artifact classification and sorting, University Press, Cambridge.

Aguarod Otal, C. 1991: Cerámica romana importada de cocina en la Tarraconense, Zaragoza.

- 2003: "Cerámica común romana: Cocina, conserva, preparación de alimentos, almacenaje y mesa", Al-Qannis 10 (El Poblado iberoromano de El Palao (Alcañiz): La Cisterna): 127-165.

Aguarod Otal, C., Felu Ortega, M. J. y Martin, J. 1995: "Aspectos técnicos de diversas producciones de cerámica común romana a través de la microscopia electrónica de barrido", Studies on Ancient Ceramics, Proceedings of the European Meeting on Ancient Ceramics. Monografies Emporitanes VIII, Barcelona: 129-154.

AlarÇAO, J. 1974: Cerámica Común local e Regional de Conimbriga, Universidad de Coimbra, Coimbra.

AlcoRTA IRASTORZA, E. J. 2001: Lucus Augusti Il: Cerámica común romana de cocina y mesa hallada en la excavaciones de la ciudad. Catalogación arqueológica y artística de Galicia del Museo de Pontevedra. A Coruña.

ALLISON, P. M. 1997: "Why do excavations reports have find's catalogues?". En C. G. Cumberpatch, and P. W. Blinkhorn, (ed.): Not So Much a Pot, More a Way of Life, Oxbow Books, Oxford: 77-84.

Appadural, A. (ed.), 1986: The social life of things: commodities in cultural perpective, Cambridge University Press, Cambridge.

Aquilué AbAdíAS, X. 1997: "Anàlisi comparativa de contextos ceràmics d'època tardorromana (V-VI) de Tarragona i Empúries", En M. Comas, et al. (ed.): Contextos cerámics d'epoca romana tardana i de l'alta edat mitjana (segles IV-X), Arqueomediterrània 2: 83-100.

Aouilué Abadías, X. y Roca Roumens, M. (ed.) 1995: Cerámica comuna romana d' època alto-imperial a la Península lbèrica : estat de la qüestió, MAC. Empuries.

ARgente Oliver, J. L. 1979: La villa tardorromana de Baños de Valdearados (Burgos). EAE 100. Madrid.

Argente Oliver, J. L. et al. 1994: Tiermes IV. La casa del acueducto: (domus alto imperial de la ciudad de Tiermes); campañas 19791986, EAE 167, Ministerio de Cultura, Madrid.

ARNoLd, D. E. 1984: "Social interaction and ceramic design: community-wide correlations in Quinua, Peru". En M. Rice (ed.): Pots and Potters: Current Approaches in Ceramic Archaeology, Insitute of Archaeology Monogrpahs 24, UCLA: 133-161.

- 1985: Ceramic theory and cultural process. Cambridge: Cambridge University Press.

ARNOLD III, P. J. 2000: "Working without a net: recent trends in ceramic ethnoarchaeology", Journal of Archaeological Research 8 (2): 105-33.

BATS, M. 1996: "Conclusions". En Bats, M. (ed.): Les cerámiques comunes de campanie et de narbonnaise (lers. av. J.-C. Iles. ap. J.-C.) La vaiselle de cuisine et de table. Centre Jean Bérard. Coll. 14, Nápoles: 481-484.

Bermejo TIRADO, J. 2007-2008: "Arqueología de las actividades domésticas: una propuesta metodológica para el mundo romano". AnMurcia 27: 227-247.

- 2011: Arqueología de los espacios domésticos: la Meseta nordeste entre el final de la Edad de Hierro y el Bajo Imperio, Tesis Doctoral. Universidad Complutense de Madrid.

Blanco Garcia, J. F. (2003): Cerámica histórica en la provincia de Segovia. I. Del Neolítico a época visigoda (V Milenio-711 d. C.), NRT Ediciones, Segovia.

Bunman, E. 1993: "Anasazi Pottery: Evolution of a Technology", Expedition 35 (1): 14-22.

BONIFAY, E. 2007: "Ceramic production in Africa during Late Antiquity: continuity and change", En L. Lavan, et al. (ed.): Technology in transition A.D. 300-650, LAA 4, Brill, Leiden-Boston: 143-158.

BONIFAY, M. 2004: Etudes sur la céramique romaine tardive d'Afrique, BAR International Series 1301, Archaeopress, Oxf ord.

BuXEDA I GaRRIGós et al. 2005: "Late Roman Coarse Ware and Cooking Wares from the Balearic Islands in Late Antiquity: Archaeology and Archaeometry". LRCW 1, BAR International Series 1340, Archaeopress, 0xford: 223-254.

CAPELLI, C. 1998: "Analisi minero-petrografiche preliminari su ceramiche di Tuburbo Maius", AntAfr 34: 251-253.

Carandini, A. y Ricci, A. (ed.) 1985: Settefinestre. Una villa schiavistica nell'Etruria romana. Vol. III. La villa e i suoi repert. Modena.

Carretero Vaquero, S. 2000: El Campamento romano del Ala ll Flavia en Rosinos de Vidriales (Zamora): La cerámica, Zamora.

Cau Ontiveros, M. A. 2003: Cerámica tardorromana de cocina de las Islas Baleares : estudio arqueométrico, BAR International Series 1182, Archaeopress, Oxford.

- 2008: Estudi arqueologic i caracterizació arqueolmètrica de la ceràmica comuna romana del Forn de Sa Mesquida (Calvià, Mallorca). El Tall, Palma de Mallorca.

Centeno, I., Palomino, A. y Villadangos Garcia, L. M. (2010): "Contextos cerámicos de la primera mitad del siglo $\mathrm{V} d$. C. en el Interior de la Meseta. El yacimiento de las Lagunillas (Aldeamayor de San Martín, Valladolid)", BSAA (Serie Arqueología) LXXVI: 91-144.

Chavarría Arnau, A. 2007: El final de las "villae" en "Hispania": (siglos IV-VII D.C), Brepols, Turnhout.

Colleti, M. y Pavolinı, C. 1996: "Ceramica comune di Ostia", En Bats, M. (ed.): Les cerámiques comunes de campanie et de narbonnaise (lers. av. J.-C. Iles. ap. J.-C.) La vaiselle de cuisine et de table. Centre Jean Bérard. Coll. 14, Nápoles, 391-419.

DeETZ, J. 1965: The dynamics of stylistic change in Arikara Ceramics, Studies in Anthropology 4, University of Illinois Press, Urbana.

Di GıovanNI, V. 1996: "Produzione e consumo di cerámica da cucina nella Campania romana (II a. C. - II d. C.)". ". En M. Bats (ed.): Les cerámiques comunes de campanie et de narbonnaise (lers. av. J.-C. 
I's. ap. J.-C.) La vaiselle de cuisine et de table. Centre Jean Bérard. Coll. 14, Nápoles: 65-103.

Dobres, M. y Hoffman, C. R. 1994: "Social Agency and the dynamics of Prehistoric Technology", Journal of Archaeological Method and Theory 1: 211-258.

Doval GalÁn, J. F. 1997-98: "Cerámica común romana del Museo Provincial de Lugo: estudio morfológico y análisis de pastas de varias piezas", Boletín del Museo Provincial de Lugo 8 (1): 19-35.

Fernández García, F. 1999: "Cerámica común romana de luliobriga en el Museo Regional del Prehistoria y Arqueología de Cantabria". En J. Manuel Iglesial y J. A. Muñiz (ed.): Regio Cantabrorum. Santander: 241-248.

Fernández OchoA, C. y Zarzalejos Prieto, M. 2001: "Reflexiones sobre una producción peculiar de cerámica común romana localizada en el tercio norte de la península Ibérica y el sur de Aquitania: los materiales de la ciudad de Gijón (España)". CuPAUAM 25 (2): 251-265.

FulfoRD, M. G. y PEACOCK, D. P. S. (ed.) 1984: Excavations at Carthage: The British Mission, Vol. I, 2, The avenue du Président Habib Bourguiba, Salambo: The Pottery and other Ceramic Objects from the site, University of Sheffield, Sheffield.

García Merino, C. 1990: "Algunas consideraciones sobre la cerámica pintada y su evolución hacia la pintura de época imperial: el caso de Uxama", AEspA 63: 115-135.

- 1991: "La Casa urbana en Uxama Argaela", En La Casa Urbana Hispanorromana. Institución Fernando el Católico, Zaragoza: 233-259.

- 1994: Uxama l:(Campañas de 1976 y 1978): Casa de la Cantera, casa del Sectile "El Tambor". EAE 170, Ministerio de Cultura, Madrid.

Garcia Merino, C. y Sánchez Simón, M. 2000: "Excavaciones en la villa romana de Almenara-Puras (Valladolid): Avance de resultados (I)", BSAA LXVII: 99-124.

Garcia Merino, C., Sánchez Simón, M. y Burón Álvarez, M. 2007: "Pinturas murales de la Casa de los Plintos. Uxama (Soria)". En Actas del IX Congreso de la AIPMA, Zaragoza: 447-450.

- 2009: "Cultura material del siglo III en un ambiente doméstico de la Meseta: el conjunto cerrado de la Casa de los Plintos de Uxama", AEspA 82: 221-253.

GASPERETI, G. 1996: "Produzione e consumo della ceramica comune da mensa e dispensa nella Campania romana", En M. Bats (ed.): Les cerámiques comunes de campanie et de narbonnaise (lers. av. J.-C. Iles. ap. J.-C.) La vaiselle de cuisine et de table. Centre Jean Bérard. Coll. 14, Nápoles: 19-63.

GRÜNEWALD, M. 1979: Die Gefäßkeramik des Legionslagers von Carnuntum: Grabungen 1968-1974, Österreichischen Akademie der Wissenschaften, Viena.

HAYES, J. W. 1972: Late Roman Pottery, British School at Rome, Londres. HeVIA, S. 2009: "Cerámica común del siglo I d. C. en el castro del Chao Samartín (Grandas de Salime, Asturias): notas sobre el repertorio en un ambiente militarizado", Limes XX: XX Congreso internaciona de estudios sobre la frontera romana (León 2006). Polifemo, Vol. 2: 639-654.

- 2009b: "Cerámica romana altoimperial de fabricación regional del Chao Samartin (Grandas de Salime, Asturias)". CuPAUAM 35: 27-190.

Illaregui Gómez, E. y Puente, M. A. 2000: "La cerámica común y de almacenaje de la villa romana de Quintanilla de la Cueza". En M. A. GARCía GuINEA (dir.): La villa romana de Quintanilla de la Cueza (Palencia): memoria de las excavaciones 1970-1981, Junta de Castilla y León: 123-156.

JÁRREGA, R. 2009: "Una nueva producción de cerámica común de mesa romana, de época altoimperial (finales del siglo II-inicios del III) en la zona de Tarraco (Tarragona)", Boletín de la SECAH 1: 22-25.

Jimeno Martinez, A., Argente Oliver, J. L. y Gómez Santa Cruz, J. 1988-1989: "La villa romana de San Pedro de Valdanzo (Soria)", Zephyrus 41-42: 419-454.

Juan Tovar, L. C. y Blanco Garcia, J. F. 1997: "Cerámica común tardorromana, imitación de sigillata, en las provincias de Segovia. Aproximación al estudio de las producciones cerámicas del siglo $\mathrm{V}$ en la
Meseta Norte y su transición al mundo hispano-visigodo". AEspA 70: 171-219.

Juan Tovar, L. C., Pérez González, C., Fernández Ibáñez, C. 1995: "Un vertedero del siglo IV d.C. en Relea (Saldaña): Campaña 1985", III Congreso de Historia de Palencia, t. I, Palencia: 381-400.

KIRCHNER, H. 2007: "Torneta y torno. Formas de producción, distribución y uso de la cerámica andalusí. El caso de Yâbisa", En A. Malpica y J. Carvajal (eds.): Estudios de cerámica tardorromana y altomedieval, ALHULIA, Granada: 223-245.

LAMOTA, V. y SCHIFFER, M. B. 1999: "Formation processes of house floor assemblages. En P. M. Allison (ed.): The Archaeology of Household Activities, Routledge, Londres: 19-29.

LARRÉN, H. et al. 2003: "Ensayo de sistematización de la cerámica tardoantigua en la cuenca del Duero". En Anejos de AEspAXXVIII: 273-306.

LEMONNIER, P. 1976: "La description des chaînes opératoires: contribution à l'analyse des systèmes techniques", Techniques Et Culture 1: 100-151.

- 1986: "The study of material culture today: toward an anthropology of technical systems", Journal of Anthropological Archaeology 5: 147-86.

- 1992: Elements for an anthropology of technology. Anthropological Papers of the Museum of Anthropology, 88, University of Michigan Press, Ann Arbor.

LONGACRE, W. A. 1991: "Sources of ceramic variability among the Kalinga of Northern Luzon", En W. A. Longacre (ed.): Ceramic Ethnoarchaeology, University of Arizona Press: 94-111.

Luezas Pascual, R. A. 1995: "Producciones cerámicas de Paredes finas y engobadas del alfar romano de "La Maja" (Calahorra, La Rioja): Hornos I y II", Berceo 128: 159-200.

- 1999: "El Instrumentum domesticum del Municipium Calagurris Iulia: I. La cerámica común romana autóctona del valle del Ebro". Kalakorikos 4: 65-82.

- 2001: "Cerámica comunes de importación de época romana en el Municipium Calagurris Iulia (Calahorra, La Rioja)". Kalakorikos 6: 71-100.

- 2001b: Cerámica común romana en La Rioja, Instituto de Estudios Riojanos, Logroño.

MaciAs SolÉ, J. M. 1999: La ceràmica comuna tardoantiga a Tarraco: anàlisi tipológica e histórica (segles V-VII), Tulcis, Monografias Tarraconenses 1. Tarragona.

- 2003: "Cerámicas tardorromanas de Tarragona: economía de mercado versus autarquia". En Anejos de AEspA XXVIII: 21-39.

MANNONI, T. 1972: "La cerámica d'uso comune in Liguria prima del secolo XIX: prime notizie per una classificazione", III Convegno internazionale della Ceramica Albisola, Savona.

Martinez SalCedo, A. 2004: La cerámica común de época romana en el País Vasco, Servicio Central de Publicaciones del Gobierno Vasco, Vitoria-Gasteiz.

MARINÉ, M. 1984: "Las "termas" de la villa de Cuevas de Soria", En I Symposium de Arqueología Soriana. Diputación Provincial de Soria, Soria: 403-415.

- 1985: Expediente 85/30 Museo Numantino Soria.

- 2007: "La villa romana de Cuevas de Soria, relato de una investigación sincopada". Arevacon 27: 17-24.

Mezouíriz, M. A. 1958: La excavación estratigráfica de Pompaelo l, campaña de 1956, Excavaciones en Navarra VIII, Pamplona.

OsunA, I. 1976: Ercavica I, Cuenca.

PANella, C. 1996: "Lo studio delle ceramiche comuni di età romana: qualche riflessione". En M. Bats (ed.): Les cerámiques comunes de campanie et de narbonnaise (lers. av. J.-C. I/'s. ap. J.-C.) La vaiselle de cuisine et de table. Centre Jean Bérard. Coll. 14, Nápoles: 9-15.

PEACOCK, D. P. S. 1982: Pottery in the roman world: an ethnoarchaeological approach, Longman, Londres.

Peinado Espinosa, M. V. 2010: Cerámicas comunes romanas en el Alto Guadalquivir: el alfar de los Villares de Andújar. Tesis doctoral, Universidad de Granada. 
PEÑA, J. T. 2007: Roman Pottery in the Archaeological Record, University Press, Cambridge.

PeÑa, J. T. y McCallum, M. 2009: "The Production and Distribution of Pottery at Pompeii: a review of evidence. Part I. Production". AJA 112 (1): $57-79$.

Puente, M. A. 2002: "Cerámica común romana de Camesa-Rebolledo". Sautuola 8: 177-228.

RAPOSO, J. et al. (e. p.): "Restitución formal y funcional de un horno romano de la alfarería de Quinta do Rouxinol, Seixal (Portugal): arqueología experimental, control de condiciones de cocción y análisis cerámico", III Congreso Internacional de Arqueología Experimental.

RECHIN, F. 1996: "La vaisselle commune de table et de cuisine en Aquitaine méridionale", En M. Bats (ed.): Les cerámiques comunes de campanie et de narbonnaise (lers. av. J.-C. Iles. ap. J.-C.) La vaiselle de cuisine et de table. Centre Jean Bérard. Coll. 14, Nápoles: 447-480.

RECHIN, F. et al. 1996: "Cerámiques communes non tournées du Nord de la Péninsule Ibérique et d'Aquitaine Meridionale. Origine et diffussion d'un type particulier de pot culinaire", SFECAG, Actes du Congrès de Dijon (1996), Marsella.

REYNOLDS, P. 1985: "Cerámica tardorromana modelada a mano de carácter regional y de importaciones en la provincia de Alicante", Lucentum IV: 245-257.

- 1993: Settlement and Pottery in the Vinalopo valley (Alicante, Spain) A.D. 400-700, Tempus Reparatum, BAR International Series 588, Archaeopress, 0xford.

- 1995: Trade in the Western Mediterranean AD 400-700: The Ceramic Evidence. Tempus Reparatum, BAR International Series 604, Archaeopress, 0xford.

- 2008: "Linear typologies and ceramic evolution", Facta 2: 61-98.

Romero Carnicero, F. 1991: Los Castros de la Edad del Hierro en el Norte de la Provincia de Soria, Studia Arqueológica, Valladolid.

Sánchez Sánchez, M. A. 1992: Cerámica común romana de Mérida (estudio preliminar). Series de Arqueología Extremeña n. ${ }^{\circ}$ 3, Cáceres.

- 1992b: "La Cerámica común". En Caballero, L. (Dir.), Arcóbriga II: Las Cerámicas romanas, Institución Fernando el Católico, Zaragoza: 247-263.
SCATOZZA HöRICHT, L. A. 1996: "Appunti sulla cerámica comune di Ercolano. Vasellame da cucina e recipienti per la preparazione degli Alimenti". En M. Bats (ed.): Les cerámiques comunes de campanie et de narbonnaise (lers. av. J.-C. Iles. ap. J.-C.) La vaiseIle de cuisine et de table. Centre Jean Bérard. Coll. 14, Nápoles: 129-156.

SCHIFFER, M. B. 1972: "Archaeological context and systemic context", American Antiquity 37: 156-65.

- 1983: "Toward the Identification of Formation Processes", American Antiquity 48 (4): 675-706.

- 1987: Formation Processes of Archaeological record. University of New Mexico Press. Albuquerque.

SCHIFFER, M.B. y SKIBO, J. 1997: "The explanation of artefact variability", American Antiquity 62 (1): 27-50.

Serrano Ramos, E. 2000: Cerámica común romana: siglos II a. C. al VII d. C. en el territorio malacitano, Studia Malacitana 16, Málaga.

SKIBO, J. 1992: Pottery function: a use-alteration perspective, Plenium, Nueva York.

Taracena AguirRe, B. 1930: "La "villa" romana de Cuevas de Soria", Investigación y Progreso IV: 78-80.

TSANTINI, E. 2004: "Caracterización arqueométrica de la cerámica común producida en la villa romana de Sa Mesquida (Mallorca)". Pyrenae 35: 137-186.

VAN DER WerfF, J. H. 1984: "Cerámique modelée d'Uzita", BaBesch 59: 125-135.

VÁzouez Gómez, X. L. y Doval Galán, J. F. 1996: "Cerámica común romana de A Coruña". Larouco 2: 119-125.

VEGAS, M. 1973: Cerámica común romana del Mediterráneo occidental, Barcelona.

VIGIL-ESCALERA, A. 2003: "Cerámicas tardorromanas y altomedievales de Madrid", En Anejos de AEspA XXVIII: 371-387.

- 2007: "Algunas observaciones sobre las cerámicas "de época visigoda" (ss. V-IX d. C.) de la Región de Madrid". En Malpica, A. y Carvajal, J. (Eds.): Estudios de cerámica tardorromana y altomedieval, ALHULIA, Granada: 359-382. 